\title{
The Effect of Public Insurance Coverage for Childless Adults on Labor Supply
}

\author{
By Laura Dague, Thomas DeLeire, and Lindsey Leininger**
}

This study provides plausibly causal estimates of the effect of public insurance coverage on the employment of non-elderly, nondisabled adults without dependent children ("childless adults"). We take advantage of the sudden imposition of an enrollment cap in Wisconsin, comparing the labor supply of enrollees to eligible applicants placed on a waitlist using a regression discontinuity design and difference-in-differences methods. We find enrollment into public insurance leads to sizable and statistically meaningful reductions in employment, with an estimated effect size of just over 5 percentage points, a 12 percent decline. Confidence intervals rule out positive and large negative effects. (JEL G22, H75, I13, I18, I38, J22)

M edicaid is currently the second most common source of insurance coverage among individuals in the United States (following private coverage from an employer). The Census Bureau estimates that Medicaid covered 19.5 percent of all individuals in 2014, up sharply from 17.5 percent in 2013 (Smith and Medalia 2015). The Affordable Care Act of 2010 (ACA) gave states the option to expand eligibility for the program to all individuals up to 133 percent of the Federal Poverty Line. To date, 32 states including the District of Columbia have done so, and this eligibility expansion largely is responsible for the increase in Medicaid coverage. This increase is also evident in administrative data. According to the Centers for Medicare and Medicaid Services (CMS), more than 72 million low income adults and children were enrolled in the Medicaid program as of January 2016, an increase of nearly 15 million since implementation of the ACA (CMS 2016).

The ACA expanded Medicaid eligibility primarily for adults and in particular for adults without dependent children, and most of the increase in enrollment was from those populations. Projections suggest that up to 21.3 million low income adults

\footnotetext{
*Dague: Texas A\&M University, 4220 TAMU, College Station, TX 77845 (e-mail: dague@tamu.edu); DeLeire: Georgetown University, 37th and O Streets, N.W., 100 Old North, Washington, DC 20057, and NBER (e-mail: thomas.deleire@georgetown.edu); Leininger: Mathematica Policy Research, 111 East Wacker Drive, Suite 920, Chicago, IL 60601 (e-mail: 1leininger@mathematica-mpr.com). This work was supported by grants from the UC Davis Poverty Center and the W.E. Upjohn Institute for Employment Research. We thank Gaston Palmucci, Chris Reynolds, Kristen Voskuil, and Kara Mandell for excellent research assistance. Alan Barreca, Kitt Carpenter, Donna Friedsam, Kosali Simon, Tim Moore, participants of the 2014 Affordable Care Act and the Labor Market conference at the Chicago Fed, and several anonymous referees provided helpful comments.

Go to https://doi.org/10.1257/pol.20150059 to visit the article page for additional materials and author disclosure statement(s) or to comment in the online discussion forum.
} 
could eventually gain coverage under the ACA Medicaid expansions (Stephens et al. 2013). ${ }^{1}$ Given the large and increasing population served by the program, knowing how Medicaid and other public health insurance programs affect the labor supply of recipients and their family members, particularly that of adults without dependent children, has become increasingly important for understanding the total costs of the program.

Economic theory predicts that cash and in-kind transfer programs generally should reduce labor supply, and extensive empirical research typically has shown that such programs do indeed have the hypothesized effect (e.g., Moffitt 2002). However, the literature on Medicaid's effect on the labor supply of low income parents is mixed. While some work finds strong work disincentives (Ellwood and Adams 1990, Moffitt and Wolfe 1992, and Dave et al. 2015), other papers find weaker disincentives or even positive incentives (Yelowitz 1995, Montgomery and Navin 2000, Ham and Shore-Sheppard 2001, 2005, Hamersma and Kim 2009, Hamersma 2013, and Strumpf 2011). These papers focus exclusively on pregnant women and parents, and the wide range of estimates arising from the existing literature suggests effects are heterogeneous across population and macroeconomic conditions studied.

A more relevant population to study given the current policy environment is low income non-elderly, nondisabled adults without dependent children ("childless adults"). We contribute to this literature by providing plausibly causal estimates of the effect of means-tested public insurance coverage on the employment of childless adults. Until the past few years, researchers have largely been unable to explore the effects of Medicaid eligibility on the labor supply of childless adults, as states have only recently begun extending coverage to this population. Garthwaite, Gross, and Notowidigdo (2014) examine eligibility contractions in Tennessee's program (TennCare), which had been available to childless adults until July 2005, and find both large reductions in Medicaid coverage and large increases in employment rates among childless adults in Tennessee following this contraction. These results are consistent with a 60 percentage point reduction in employment stemming from the availability of public insurance. Baicker et al. (2014) examined the impacts of Medicaid on the employment of recipients through the Oregon Health Insurance Experiment and found modest reductions in employment, of 1.6 percentage points, that are not statistically different from zero. Notably, and in keeping with the earlier literature, results from this newer work on childless adults are characterized by considerable heterogeneity across population and economic context.

Because the size of the labor supply disincentive effects of public insurance likely vary with the economic environment, it is important to obtain a variety of estimates. This is especially true given the extreme divergent results found in the two recent papers discussed above (Garthwaite, Gross, and Notowidigdo 2014 and Baicker et al. 2014). Learning about the likely labor market effects of the ACA on low income childless adults is also of critical policy importance. The Congressional Budget Office (CBO) estimated that the ACA would reduce total labor market activity (as measured by the total number of hours worked) by roughly $1.5-2$ percent,

\footnotetext{
${ }^{1}$ Approximately half of these projected new adults lived in states where, as of March 5, 2013, governors either had not yet decided to expand or opposed the Medicaid expansion.
} 
representing a decline of approximately 2 million full-time-equivalent workers. Moreover, the $\mathrm{CBO}$ attributes this projected decline primarily to a decrease in labor supply (Congressional Budget Office 2014).

In this study, we exploit a recent policy reversal in Wisconsin, during which a major public insurance expansion for childless adults was implemented and, several months later, abruptly frozen. Individuals who applied after the program was frozen were placed on a waitlist. Those on the waitlist were supposed to have been allowed to enroll as space became available due to exits from the program, and it was generally understood in the months following the establishment of the waitlist that this was how it would operate. However, entry from the waitlist never occurred even as the Core Plan enrollment declined. We obtain estimates of the causal effect of Medicaid on the labor supply of childless adults by comparing the labor market outcomes of those who applied prior to the program freeze and received benefits to those who applied after the program freeze and did not receive benefits.

We use both a regression discontinuity design that employs the timing of the enrollment suspension and waitlist introduction and a fixed effects difference-in-differences model that fully exploits the strengths of our individual-level panel data and removes time-invariant unobserved differences between the two groups to estimate the size of these effects. An important challenge is that the waitlist was announced a few days prior to its implementation, inducing a large number of applications. We take numerous steps to address this issue. In addition to showing that estimates are robust to various alternative specifications, we show that there is no evidence of a difference in self-reported health needs for those who applied during that time nor is there evidence of differential prior health care usage between waitlisted applicants and recipients.

A particular strength of our study is that we rely on the state's own administrative records rather than on self-reported enrollment, employment, and earnings data. The data for our study are Medicaid enrollment files merged with quarterly unemployment insurance earnings reports from Wisconsin. The Medicaid records allow us to observe all enrolled and waitlisted applicants, including their exact date of application. The unemployment insurance earnings records are from employer reporting to the state and allow us to observe quarterly wages from all employers, changes in employer, and any spells of nonemployment lasting more than one quarter. The large size of our matched administrative dataset allows us to explore whether effects are different for particular demographic subgroups, including age and sex, and whether they might vary across business cycles by looking at variation in local unemployment rates and effects on industrial employment, an important contribution given the heterogeneity in previous findings.

We find public insurance enrollment reduces the likelihood an adult in our sample will be employed by 5.2 percentage points and reduces net earnings by over $\$ 315$ per quarter over the following nine quarters, according to our regression discontinuity estimates. Our fixed effects difference-in-difference estimates yield a similar effect size of a 5.3 percentage point reduction in employment and a $\$ 74$ reduction in earnings. The 95 percent confidence intervals for these estimates rule out either any positive effect or large negative effect of public health insurance on labor supply. Effects are largest for those with ages over 55, and there is evidence of interaction between 
individual employment status and the local labor market conditions in whether public insurance discourages work. These effect sizes are an order of magnitude smaller than those found by Garthwaite, Gross, and Notowidigdo (2014) and are three times larger than those found by Baicker et al. (2014). Though much smaller than one estimate, our results show that enrollment of childless adults into public insurance can lead to economically and statistically meaningful reductions in labor supply.

\section{Background}

Launched in January 2009, Wisconsin's BadgerCare Plus Core Plan provided health insurance to childless adults with household incomes below 200 percent of the Federal Poverty Line (FPL). The state of Wisconsin applied for and received a federal Section 1115 waiver to extend some health benefits to this population. Once enrolled, members received a managed care benefit package and faced little cost-sharing. With few exceptions, coverage was not available to persons who already had any form of private health insurance, quit their job, or voluntarily dropped any health insurance in the 12 months prior to application. The program initially required a $\$ 60$ application fee. Upon enrollment, members were eligible to receive benefits for a period of 12 months, when eligibility would be reevaluated.

Enrollment began January 1, 2009 for a limited group and opened to the public on July 1,2009. Application levels immediately exceeded projections and program budget, with enrollment reaching a high of 65,057. On October 5, 2009, then-Governor Jim Doyle announced at a news conference that Core Plan applications would be suspended effective October 9, 2009 at noon. The suspension was stated by the governor to result from unanticipated demand for the program and was reported in newspapers statewide.

Eligible applications received after noon on October 9, 2009 were placed on a waitlist. Waitlisted applicants were not required to pay the application fee, and were told that once openings in Core were available they would be notified. The waitlist had reached 89,412 individuals by December 2010. The state has sought to decrease overall Core Plan enrollment to a sustainable level, and thus did not enroll waitlisted applicants as enrolled Core Plan members left the program. The only waitlisted applicants ever enrolled were a small number who were eligible for a medical waitlist bypass because of cancer or heart disease. ${ }^{2}$ The presence of a waitlist, imposed quickly based only on state budget criteria and not on participant characteristics, provides a natural and ready comparison group for those enrolled in the Core Plan. Those on the waitlist wanted to and were eligible to enroll, but were not able to do so before the enrollment suspension went into effect. Names were not removed from the waitlist if later income should change.

\footnotetext{
${ }^{2}$ A program with more limited benefits, called the BadgerCare Plus Basic Plan, was promised for waitlisted applicants at the time of the announcement. The Basic Plan was formally announced in January 2010 and coverage was eventually offered to those enrolled on the waitlist effective in July 2010. The state legislature required the Basic Plan to be self-supporting through premiums. Participants in Basic were required to remain eligible for the Core Plan; this meant, among other requirements, their incomes had to remain below the 200 percent FPL threshold. Enrollment in the Basic Plan reached a high of 6,013 in April 2011 (reflecting March applicants) and has steadily declined since then.
} 
While outside the window of our study, Wisconsin chose not to participate in federally incentivized Medicaid expansions under the ACA. However, effective April 1, 2014, all childless adults with income under 100 percent FPL were allowed to enroll in the Medicaid program and all adults with incomes over 100 percent FPL were required to transition out of the program, ending the BadgerCare Plus Core Plan. The net change in state program enrollment as of January 2016 relative to before ACA implementation has been an increase of 6.1 percent, while nationally enrollment was up 26.5 percent (CMS 2016). ${ }^{3}$

\section{Theory and Related Literature on Transfer Programs}

A standard static labor supply model would predict that income eligibility thresholds for public health insurance likely reduce the incentive to remain in or return to the workforce and, among workers, likely reduce the incentive to increase work hours. The negative effect on labor supply results from the reduced need for private coverage among recipients as well as the possibility that increased earnings would disqualify them from public coverage (the "Medicaid notch").

As discussed above, the existing economics literature portrays a mixed picture of the impact of Medicaid eligibility on the labor supply of both low income parents and childless adults. In contrast, the literature on other important publicly provided health insurance programs is more conclusive. French and Jones (2011) show Medicare eligibility is an important determinant of retirement decisions. Boyle and Lahey (2010) find decreased labor supply on both the extensive and intensive margins for older veterans eligible for Department of Veterans Affairs health programs.

An important distinction between the Wisconsin Core Plan for childless adults and Medicaid to childless adults in general is that following the imposition of the enrollment cap on October 9, 2009, the Core Plan was no longer an entitlement. That is, after October 9, 2009, any Core Plan member who left the plan (perhaps as a result of gaining health insurance through a new employer) would not be able to go back on the plan should he or she subsequently lose private insurance. This would not be the case with Medicaid; individuals would be free to exit and reenter the program as their eligibility changes. The fact that the Core Plan was not an entitlement may have had a "lock-in" effect on enrollees, exacerbating any employment disincentive relative to that of Medicaid.

Other types of cash and in-kind transfer programs in the United States have been found to negatively affect labor supply. Moffitt (2002) reviews the extensive empirical literature. More recently, Jacob and Ludwig (2012) find a 6 percent decline in labor force participation and a 10 percent decrease in earnings resulting from housing vouchers. Hoynes and Schanzenbach (2012) find reductions in employment and hours worked among single-headed households resulting from the food stamp program. Meyer (2002) finds the Earned Income Tax Credit, which subsidizes work for low income families, encourages work for single mothers on the extensive but not on

\footnotetext{
${ }^{3}$ Those without access to affordable health insurance and with family incomes higher than 100 percent FPL could be eligible for premium tax credits and cost-sharing reductions in Wisconsin's federally facilitated health insurance exchange.
} 
the intensive margin; Eissa and Hoynes (2004) find extensive margin work disincentives for married couples. Social Security Disability Insurance has generally been found to reduce employment among older men (Bound 1989; Parsons 1991; Gruber and Kubik 1997; Chen and van der Klaauw 2008; Maestas, Mullen, and Strand 2013; and French and Song 2014). Given differences across transfer programs in both size and income testing of the associated benefit, we must exercise caution in extrapolating results to the Medicaid context. That said, it is important to recognize that the broader literature on non-health-insurance-based transfer programs consistently finds a negative association between program eligibility and labor supply.

The effect of Medicaid is ambiguous in our context. If availability of public insurance leads to increased job mobility and increased mobility results in better job matches, we could, all else equal, observe higher wages (and therefore earnings) among the public insurance enrollees. A second possibility is that workers could match with jobs that pay higher wages since the job would no longer need to pay health benefits. Baicker and Chandra (2006) find increases in health insurance premiums result in both a decreased probability of employment and lower wages, supporting a partial wage offset for health insurance. Since we do not observe hours worked, only quarterly earnings, in practice, earnings could either increase (because of better matches and/or wage offsets) or decrease (because of fewer hours worked). Again, since workers must remain below the income eligibility threshold, the positive effects are likely limited. Another possibility is that the availability of Medicaid could improve health, reducing the disutility of work and increasing labor supply.

Finally, increased availability of public insurance may increase the likelihood a worker would become self-employed. Consistent with a compensating differential framework, the self-employment wage is effectively increased by the value of public insurance coverage. Results from the empirical literature are mixed (Lombard 2001; Holtz-Eakin, Penrod, and Rosen 1996; Zissimopoulos and Karoly 2007; and Fairlie, Kapur, and Gates 2011); however, we acknowledge the possibility and discuss it further below.

\section{Data}

The data sources for this project are state administrative records on enrolled and waitlisted Core Plan applicants and earnings records from Wisconsin's unemployment insurance (UI) system. In the state's records on Core Plan enrollees and waitlisted applicants, we observe exact application date, age in months, monthly income at the time of application, county of residence, and sex. The UI data include quarterly earnings for each individual from each covered firm where he or she worked during that quarter, as well as the four-digit North American Industry Classification System (NAICS) industry code for the firm. Only employers not subject to unemployment insurance laws (for example, the self-employed) are exempt from the reporting requirement. We observe these data for each person from the first quarter of 2005 (2005:I) through the final quarter of 2011 (2011:IV). We merge the data on Core Plan applicants and enrollees to the UI data using Social Security numbers.

A particular strength of our analysis is that UI data exhibit superior accuracy over the survey-based data used in the existing literature. Virtually all employers 
are required to file quarterly wage reports for each employee on their payrolls. The wage reports include the employee's Social Security number and quarterly wages and the employer's federal tax identification number and industry classification code. Using these data, we can track quarterly earnings and employment at all covered firms, changes in employer, and any periods of nonemployment lasting for at least one quarter.

We consider several outcomes to measure labor supply using the quarterly employment records available in the UI data. For employment, we consider average quarterly employment over the 2009:IV to 2011:IV period, with employment defined as having any earnings in a quarter, reflecting all available quarters in the post-waitlist era. We also present results that treat employment in each quarter separately in order to consider how the behavior of applicants may have changed over time, since their beliefs about whether they would ever get insurance may have changed and this would not be reflected in the average outcome. Earnings are defined as average earnings over 2009:IV to 2011:IV. For the difference-in-differences models and for tests of the regression discontinuity assumption as described below, these outcomes are defined analogously for the preprogram period.

The time period of the analysis includes the Great Recession, and Wisconsin was no exception to the nation's overall poor economic performance during this time. It is possible that the recession influenced the likelihood that those reentering the labor force changed industries, which may be more costly than a typical job transition, and therefore suppressed labor supply among those who received the insurance relative to a non-recessionary period. For this reason, and to explore differences in our results relative to other recent work, we include analyses by local unemployment rate in 2009 and by industry. The source for the local unemployment data is the Bureau of Labor Statistics' Quarterly Census of Employment and Wages.

When examining industry, we aggregate to two digit NAICS codes and identify the top five industries for tractability. These industries are: Accommodation and Food Services (code 72); Retail Trade (codes 44-45); Administrative and Support and Waste Management and Remediation Services (code 56); Manufacturing (codes 31-33); and Health Care and Social Assistance (code 62). We classify individuals employed at more than one firm during a quarter as employed in the industry from which they received the majority of their wages.

Waitlist members were subject to basic screening, but to ensure comparability we employ several sample filters to confirm those on the waitlist would have actually been eligible for the Core Plan had they been invited to enroll (on the basis of all characteristics other than earnings, which may have changed in response to being on the waitlist). First, we drop anyone not in the eligibility age range (ages 19-64) according to date of birth. Second, we observe termination codes (reasons) for waitlist members that are removed from the waitlist, and we drop all waitlist members with codes indicating they either do not meet program requirements or are eligible for other Medicaid programs. We do not observe Core Plan applicants who applied before the program cutoff and were found ineligible by the state.

Table 1 reports demographic characteristics as well as pre-period and post-period outcomes for two groups: all Core and waitlist applications in our sample, regardless of application date, and just those who applied within 30 days of October 9, 2009. 
Table 1 -Demographic Characteristics, Core Plan Enrollees versus Waitlisted Applicants

\begin{tabular}{|c|c|c|c|c|c|}
\hline & \multicolumn{2}{|c|}{$\begin{array}{l}\text { Core plan } \\
\text { enrollees }\end{array}$} & \multicolumn{2}{|c|}{$\begin{array}{l}\text { Waitlisted } \\
\text { applicants }\end{array}$} & \multirow[t]{2}{*}{$p$-value } \\
\hline & Mean & $\mathrm{SD}$ & Mean & SD & \\
\hline \multicolumn{6}{|l|}{ Ever applied } \\
\hline Age & 43.6 & 13.5 & 38.9 & 13.4 & 0.000 \\
\hline Female & $49.6 \%$ & 0.500 & $43.0 \%$ & 0.496 & 0.000 \\
\hline Percent employed, 2009:II & $43.2 \%$ & 0.495 & $48.3 \%$ & 0.500 & 0.000 \\
\hline Average quarterly earnings, 2009:II & 1,247 & 2,174 & 1,828 & 3,000 & 0.000 \\
\hline Percent accommodation and food service, 2005:I-2009:II & $9.5 \%$ & 0.22 & $9.2 \%$ & 0.21 & 0.054 \\
\hline Percent retail trade, 2005:I-2009:II & $8.5 \%$ & 0.20 & $8.3 \%$ & 0.20 & 0.177 \\
\hline $\begin{array}{l}\text { Percent administration and support and waste management, } \\
\text { 2005:I-2009:II }\end{array}$ & $6.9 \%$ & 0.16 & $6.8 \%$ & 0.15 & 0.250 \\
\hline Percent manufacturing, 2005:I-2009:II & $7.8 \%$ & 0.21 & $8.2 \%$ & 0.22 & 0.001 \\
\hline Percent health care and social assistance, 2005:I-2009:II & $5.6 \%$ & 0.18 & $5.0 \%$ & 0.18 & 0.000 \\
\hline Average employment, 2009:IV-2011:IV & $42.8 \%$ & 0.41 & $48.3 \%$ & 0.38 & 0.001 \\
\hline Average earnings, 2009:IV-2011:IV & 1,509 & 2,098 & 1,724 & 2,141 & 0.000 \\
\hline Observations & \multicolumn{2}{|c|}{42,401} & \multicolumn{2}{|c|}{60,507} & \\
\hline \multicolumn{6}{|l|}{ Applied within 30 days of October 9, 2009} \\
\hline Age & 42.2 & 13.5 & 39.1 & 13.2 & 0.000 \\
\hline Female & $46.9 \%$ & 0.499 & $44.8 \%$ & 0.497 & 0.032 \\
\hline Percent employed, 2009:II & $44.7 \%$ & 0.497 & $48.3 \%$ & 0.500 & 0.000 \\
\hline Average quarterly earnings, 2009:II & 1,449 & 2,649 & 1,625 & 2,711 & 0.001 \\
\hline Percent accommodation and food service, 2005:I-2009:II & $9.5 \%$ & 0.21 & $9.9 \%$ & 0.21 & 0.401 \\
\hline Percent retail trade, 2005:I-2009:II & $8.3 \%$ & 0.19 & $9.0 \%$ & 0.20 & 0.087 \\
\hline $\begin{array}{l}\text { Percent administration and support and waste management, } \\
\text { 2005:I-2009:II }\end{array}$ & $6.8 \%$ & 0.15 & $7.2 \%$ & 0.15 & 0.266 \\
\hline Percent manufacturing, 2005:I-2009:II & $8.2 \%$ & 0.22 & $8.3 \%$ & 0.22 & 0.812 \\
\hline Percent health care and social assistance, 2005:I-2009:II & $5.0 \%$ & 0.17 & $4.9 \%$ & 0.17 & 0.855 \\
\hline Average employment, 2009:IV-2011:IV & $43.7 \%$ & 0.40 & $49.4 \%$ & 0.39 & 0.000 \\
\hline Average earnings, 2009:IV-2011:IV & 1,562 & 2,132 & 1,816 & 2,241 & 0.000 \\
\hline Observations & \multicolumn{2}{|c|}{10,528} & \multicolumn{2}{|c|}{3,396} & \\
\hline
\end{tabular}

Notes: The table shows means and standard deviations of selected characteristics, along with the $p$-values for a two-tailed test of the difference in means. Age and sex are from application data. Average employment, earnings, and industry are constructed from unemployment insurance reporting data.

We note that while Core recipients had to apply between June 15 and October 9 , 2009, waitlist applications in our data could take place anytime between October 9 , 2009 and mid-2011. Overall, individuals who enrolled in the Core Plan are aged 43.6 on average and 49.6 percent were female, while the average age for those on the waitlist was lower- 39 years - and 43 percent were female. If we examine only those who applied within about a month of the October 9 cutoff date (i.e., those who enrolled into Core between September 1, 2009 and October 2, 2009 and those who were waitlisted and applied between October 9, 2009 and October 31, 2009), these differences are smaller. Employment across the top five industries is very similar for the two groups.

The average Core enrollee was slightly less likely to be employed in the second quarter of 2009 than the average waitlisted applicant, and had lower average earnings; again, these differences are smaller in the subset of applicants who applied within 30 days of waitlist implementation. Figure 1 plots quarterly employment rates for those enrolled in the Core Plan and those waitlisted from 2005:I to 2011:IV for all individuals who applied within 30 days of the cutoff date. The first plot of Figure 1 (panel A) illustrates the simple unweighted average employment of the two 
Panel A. Applications within 30 days

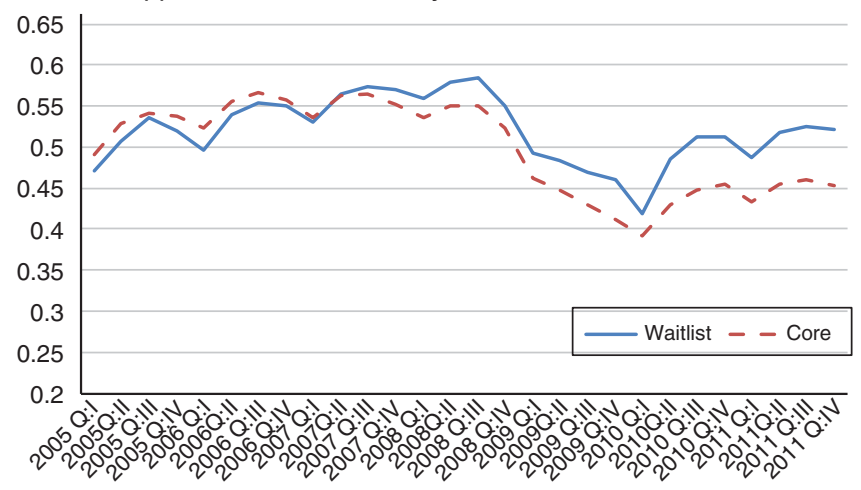

Panel B. Applications within 30 days, propensity score adjusted

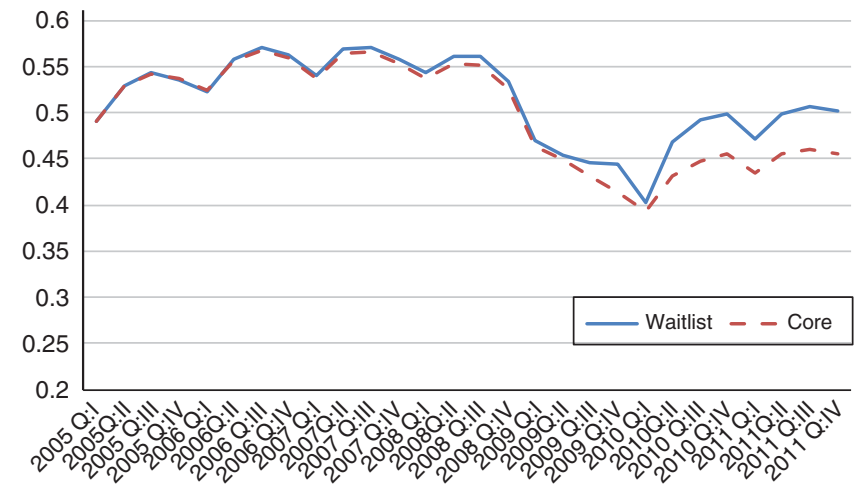

Panel C. Estimated difference in probability of employment

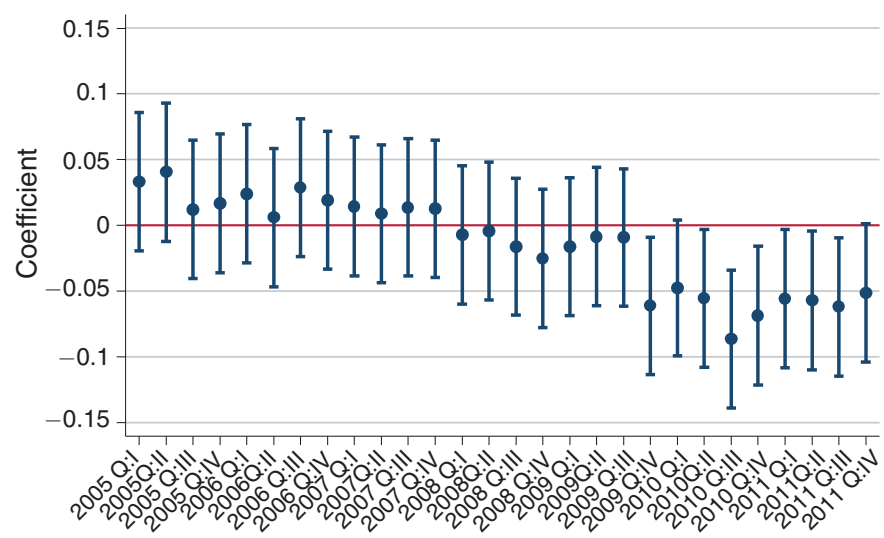

Quarter

Figure 1. Average Employment by Quarter, Core versus Waitlist

Notes: Panel A shows average quarterly employment for all applicants by Core versus waitlist status. Panel B shows the same outcome with observations weighted by the propensity score. Panel C shows the raw estimated difference in the probability of employment with 95 percent confidence intervals, where the estimate treats each quarter as a separate outcome in the regression discontinuity design. 
groups. The second plot (panel B) weights observations by an estimated propensity score (details of which are provided in the section on the difference-in-differences estimates). The final plot (panel C) in Figure 1 shows the estimated difference in the two groups' employment status treating each quarter separately. In particular, we use the regression discontinuity design described in the next section and by equation (1), so that the dot above 2005:I represents the point estimate of the difference between the Core and waitlist groups in the first quarter of 2005, while the line represents the standard error on the estimate, and equivalently for each other quarter in turn. We implement this at a bandwidth of 20 days with no covariate adjustments.

A few things should be noted from Figure 1. First, Core Plan enrollees and waitlisted enrollees both suffered large declines in employment rates around 2009:II-III, bottoming out in about 2010:I, suggesting that employment losses (and perhaps loss of employer sponsored insurance coverage) led many to apply to the Core Plan. Second, Core Plan enrollees tended to have slightly lower average employment rates in the quarters leading up to the date when enrollment into the plan opened in July 1, 2009 than did waitlisted applicants, suggesting some statistical adjustment or quasi-experimental design is needed. Third, waitlisted applicants had higher employment rates in the quarters following the cutoff date, suggesting a substantial employment disincentive effect of public insurance. Finally, Figure 1 makes clear that in both the propensity score adjusted comparison and the regression discontinuity design, there are no statistically significant differences in pre-period labor market outcomes; all differences in the two groups begin after the difference in their insurance coverage begins in the third quarter of 2009.

\section{Regression Discontinuity Estimation}

Our main approach in identifying the effect of the Core Plan on the labor supply of childless adults is a regression discontinuity design. Lee and Lemieux (2010) provide an overview and summary of recent applications. In essence, this approach involves comparing the labor supply of those who applied just prior to October 9 , 2009 (immediately before the enrollment cap was implemented) with the labor supply of those who applied just after October 9, 2009 (immediately after the enrollment cap was set). As discussed above, eligible applicants who applied prior to October 9 were enrolled into the program while those who applied after October 9 were placed on a waiting list. Because all eligible people who applied before October 9 were allowed to enroll in the Core Plan and none who applied after were, we use a "sharp" regression discontinuity design.

Importantly, the date was announced precipitously (on October 5) and would have been unexpected by all potential applicants. However, the data show the announcement resulted in an increase in applications between October 5 and October 9. Online Appendix Figure 1 makes clear the increase in applications during the last week. ${ }^{4}$

\footnotetext{
${ }^{4}$ We can also see in online Appendix Figure 1 that applications were allowed on weekends during the post-period and not during the pre-period, resulting in an increase on Mondays. Documentation from the time indicates that the computer system used for Core Plan applications processed them the next business day if received after 4:30 PM or on a weekend. When the waitlist was initiated, the State was unable to use the same system and initially recorded applications in a spreadsheet, and applications appear to have been recorded on the day in which they occurred,
} 
Our preferred specifications use only the data on enrollees up to the announcement date and exclude an equal interval before and after the waitlist implementation date (applications from October 5-October 14 are discarded with the implicit assumption that applications were displaced from just after the ninth to just before). 5

The RD approach enjoys a distinct advantage over simple comparisons of those enrolled in the Core Plan with those on the waiting list. Since the cutoff date was imposed arbitrarily by the state (and was not an original feature of the program), it is reasonable to assume the individuals applying just before the announced cutoff date were very similar to those applying just after the cutoff date. The standard RD identification assumption applies, and in this context is interpreted as: there is no self-selection into application based on the knowledge the applicant will be on the waitlist rather than gain immediate insurance. We implement our estimates using a local linear regression approach. We include robustness checks to various bandwidths as part of our analysis. The standard validity checks are included in the online Appendix and are discussed in more detail in the results section.

The exact specification of our RD estimator is

$$
Y_{i}=\alpha+\theta\left(X_{i}-x_{0}\right)+\tau W_{i}+\gamma\left(X_{i}-x_{0}\right) W_{i}+\epsilon_{i},
$$

with triangular kernel weights, where all observations outside the bandwidth $h$ (more than $h$ away from $x_{0}$ ) are discarded. Here, $Y_{i}$ is the outcome under consideration; $X_{i}$ is the date of application; $x_{0}$ is the cutoff date; $W_{i}$ is an indicator for whether or not the individual was enrolled in Medicaid (equals zero if on the waitlist, one if in Core); and $\epsilon_{i}$ is a random error term. The treatment effect of interest is $\tau$. The coefficients $\theta$ and $\gamma$ allow the slope of the regression to differ on either side of the cutoff $x_{0}$.

For the main analysis, we select a bandwidth of 20 days, which includes applications from September 15-October 4 and October 15-November 3. Because the announcement prior to the actual application cutoff date makes the identification less straightforward than might be desired, we take several further steps. ${ }^{6}$ First, we perform numerous robustness checks involving alternative choices of included application dates, including specifications that include applications between October 5 and 9. These are included at the end of this section. Second, we also provide estimates based on a second approach: matched and unmatched difference-in-differences models with individual fixed effects. We discuss these models and their results in Section VI.

including weekends. This motivates controls for day of week of application. We also estimated models defined by application week (Saturday-Friday) rather than day. Results are very similar and available upon request.

${ }^{5}$ This is similar to the "donut-RD" estimate studied in Barreca, Lindo, and Waddell (2016) as a solution to heaping bias. We have performed additional analyses that allow for varying periods of displacement. In particular, we excluded applications up to two weeks, three weeks, and four weeks after the waitlist; in addition, we performed a simulation that studies the implications of redistributing the surge applications throughout the post-period. We give individuals their actual labor supply to be conservative; since they did receive the program but we classify them as not receiving it, this should bias against finding a result. The size of the coefficient in each analysis is very similar to that obtained by the one week analysis. These results are available upon request.

${ }^{6}$ Specifically, we might be concerned the announcement is a form of manipulation and affects waitlisted applicants in the post-period in addition to those who enrolled during the few days between the announcement and the suspension of enrollment. 


\section{A. Regression Discontinuity Results}

The first outcome we examine is the probability of employment, defined as the fraction of quarters with nonzero earnings from the fourth quarter of 2009 to the last quarter of 2011. ${ }^{7}$ Results of the estimation are summarized in the first row of the first column of Table 2. At the reported bandwidth of 20 days, the point estimate is a difference of -5.2 percentage points in the specification that includes covariates (sex, employment in prior quarter, earnings in prior quarter, age modeled with indicators for every five years, and indicators for day of week of application), which is statistically different from zero at the 5 percent level. In other words, Core recipients who had access to public health insurance were just over 5 percentage points less likely to be employed after getting that insurance relative to waitlisted applicants who did not get access. Relative to the average second quarter of 2009 employment of Core recipients who applied within 30 days ( 44.7 percent), this is a 12 percent reduction in labor supply. We note that as seen in Figure 1, both Core recipients and waitlisted applicants were increasing their labor supply throughout most of this period; as such, this relative difference means that the waitlisted applicants increased their labor supply by a larger amount, not necessarily that Core recipients were quitting jobs or reducing hours worked.

Figure 2 illustrates the results of our local linear RD specification for this outcome. We plot the assignment variable (day of application) on the $x$-axis and the outcome variable (average quarterly employment from 2009:IV to 2011:IV) on the $y$-axis. Each observation is the average of the outcome for all applicants on that day and the lines are the estimated local linear regression functions (with no adjustment for covariates). Like the regression analysis, this plot excludes the week prior to and after the cutoff day. The figure shows application dates within the 20-day bandwidth, from September 15 to October 4 and from October 15 to November 3. The difference in average employment between the Core recipients and waitlisted applicants is made obvious in this figure, consistent with the results presented in Table 2.

Figure 2 also includes a bandwidth robustness illustration for this specification, which shows the effect of changing the number of days around the cutoff date that are included in the local linear estimation. Because of the tradeoff between higher variability at lower bandwidths and potential bias from including data too far from the relevant threshold at higher bandwidths, we show the results as a function of this parameter to assure the reader that the results are not dependent in an important way on the exact interval. In this, the $x$-axis is the bandwidth at which the specification was estimated, while the $y$-axis is the size of the estimate. The solid dark line represents the estimate itself, and the lighter dashed lines represent the 95 percent confidence interval for the estimate. After some variability at the smallest bandwidths, the point estimate is robust to changing the exact bandwidth used for estimation. Increasing the bandwidth decreases the standard error on the estimate but does not change the point estimate in a meaningful way.

\footnotetext{
${ }^{7}$ We have also performed the estimation excluding the final quarter of 2009 with nearly identical results.
} 
Table 2-Summary of Regression Discontinuity Results, Employment Outcomes

\begin{tabular}{|c|c|c|c|c|}
\hline & $\begin{array}{l}\text { Average quarterly } \\
\text { employment rate, } \\
\text { 2009:IV-2011:IV }\end{array}$ & $\begin{array}{l}\text { Ever employed, } \\
2010\end{array}$ & $\begin{array}{l}\text { First-differenced } \\
\text { employment rate }\end{array}$ & $\begin{array}{l}\text { Average quarterly } \\
\text { earnings, } \\
\text { 2009:IV-2011:IV }\end{array}$ \\
\hline $\begin{array}{l}\text { Regression discontinuity } \\
\text { estimate }\end{array}$ & $\begin{array}{cc}-0.052 & -0.055 \\
(0.025) & (0.029)\end{array}$ & $\begin{array}{cc}-0.056 & -0.059 \\
(0.033) & (0.036)\end{array}$ & $\begin{array}{cc}-0.069 & -0.079 \\
(0.028) & (0.028)\end{array}$ & $\begin{array}{cc}-315.9 & -314.2 \\
(150.3) & (164)\end{array}$ \\
\hline Female & $\begin{array}{c}0.084 \\
(0.010)\end{array}$ & $\begin{array}{c}0.066 \\
(0.013)\end{array}$ & $\begin{array}{c}0.038 \\
(0.011)\end{array}$ & $\begin{array}{l}160.8 \\
(58.4)\end{array}$ \\
\hline Earnings 2009:II (\$1,000s) & $\begin{array}{c}0.002 \\
(0.003)\end{array}$ & $\begin{array}{r}-0.006 \\
(0.003)\end{array}$ & $\begin{array}{r}-0.014 \\
(0.003)\end{array}$ & $\begin{array}{l}233.1 \\
(70.5)\end{array}$ \\
\hline Employed 2009:II & $\begin{array}{c}0.369 \\
(0.014)\end{array}$ & $\begin{array}{c}0.405 \\
(0.016)\end{array}$ & $\begin{array}{c}0.015 \\
(0.015)\end{array}$ & $\begin{array}{c}768.4 \\
(226.2)\end{array}$ \\
\hline $\begin{array}{l}\text { Age controls (19-24 exclude } \\
\qquad[24-29)\end{array}$ & $\begin{array}{c}0.005 \\
(0.019)\end{array}$ & $\begin{array}{r}-0.022 \\
(0.023)\end{array}$ & $\begin{array}{r}-0.173 \\
(0.020)\end{array}$ & $\begin{array}{l}319 \\
(99.5)\end{array}$ \\
\hline$[29-34)$ & $\begin{array}{r}-0.016 \\
(0.021)\end{array}$ & $\begin{array}{r}-0.030 \\
(0.026)\end{array}$ & $\begin{array}{r}-0.214 \\
(0.023)\end{array}$ & $\begin{array}{c}268.6 \\
(118.1)\end{array}$ \\
\hline$[34-39)$ & $\begin{array}{c}-0.036 \\
(0.024)\end{array}$ & $\begin{array}{r}-0.066 \\
(0.031)\end{array}$ & $\begin{array}{c}-0.219 \\
(0.025)\end{array}$ & $\begin{array}{c}146.6 \\
(136.6)\end{array}$ \\
\hline$[39-44)$ & $\begin{array}{r}-0.067 \\
(0.024)\end{array}$ & $\begin{array}{r}-0.113 \\
(0.031)\end{array}$ & $\begin{array}{r}-0.276 \\
(0.026)\end{array}$ & $\begin{array}{c}168.3 \\
(147.1)\end{array}$ \\
\hline$[44-49)$ & $\begin{array}{c}-0.107 \\
(0.022)\end{array}$ & $\begin{array}{c}-0.133 \\
(0.028)\end{array}$ & $\begin{array}{r}-0.274 \\
(0.023)\end{array}$ & $\begin{array}{l}-21.64 \\
(126.5)\end{array}$ \\
\hline$[49-54)$ & $\begin{array}{c}-0.136 \\
(0.020)\end{array}$ & $\begin{array}{c}-0.195 \\
(0.026)\end{array}$ & $\begin{array}{c}-0.325 \\
(0.030)\end{array}$ & $\begin{array}{l}-264.3 \\
(114.1)\end{array}$ \\
\hline$[54-59)$ & $\begin{array}{c}-0.164 \\
(0.021)\end{array}$ & $\begin{array}{c}-0.243 \\
(0.027)\end{array}$ & $\begin{array}{r}-0.329 \\
(0.024)\end{array}$ & $\begin{array}{r}-386.5 \\
(118.2)\end{array}$ \\
\hline$[59-64)$ & $\begin{array}{c}-0.178 \\
(0.022)\end{array}$ & $\begin{array}{c}-0.243 \\
(0.028)\end{array}$ & $\begin{array}{c}-0.321 \\
(0.025)\end{array}$ & $\begin{array}{c}-455.4 \\
(124.9)\end{array}$ \\
\hline $64+$ & $\begin{array}{c}-0.355 \\
(0.038)\end{array}$ & $\begin{array}{r}-0.479 \\
(0.053)\end{array}$ & $\begin{array}{r}-0.476 \\
(0.057)\end{array}$ & $\begin{array}{r}-1,252.7 \\
(161.4)\end{array}$ \\
\hline $\begin{array}{l}\text { Application day of week } \\
\text { indicators }\end{array}$ & $\mathrm{X}$ & $\mathrm{X}$ & $\mathrm{X}$ & $\mathrm{X}$ \\
\hline \multicolumn{5}{|l|}{ Mean of outcome variable } \\
\hline In-sample waitlist & 0.490 & 0.629 & -0.043 & $1,816.6$ \\
\hline In-sample core & 0.425 & 0.563 & -0.093 & $1,489.6$ \\
\hline Observations & 6,064 & 6,064 & 6,064 & 6,064 \\
\hline
\end{tabular}

Notes: Table displays regression discontinuity estimates of effect of getting the Core Plan, with robust standard errors in parentheses. All estimates exclude one week prior to and following the waitlist implementation. Slope coefficients for assignment variable are not included in the table. Average quarterly employment rate is defined as the fraction of quarters with nonzero earnings. First-differenced employment rate is calculated as the difference in average quarterly employment in the post-period (2009:IV to 2011:IV) and the pre-period (2005:I to 2009:II). Results calculated at a bandwidth of 20 days. Figures 2-4 illustrate data for average quarterly employment rate, first-differenced employment rate, average quarterly earnings, and show bandwidth robustness. Bandwidths are defined as distance from excluded interval.

Table 2 also includes a specification that does not include observable pretreatment covariates in the second column. The inclusion of covariates should not change the point estimate if the identification assumption behind the regression discontinuity design holds. Including covariates also increases precision of the estimates. When we do not include covariates the estimate is -5.5 percentage points and is statistically different from zero at the 10 percent level. This is almost identical to 
Panel A. Excludes October 5-October 14

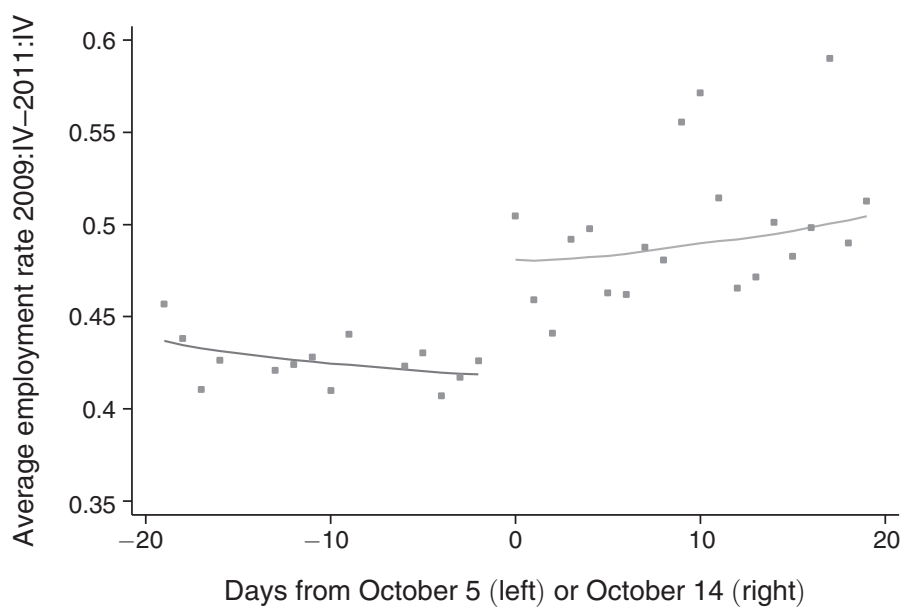

Panel B. Estimate and 95\% confidence interval by bandwidth

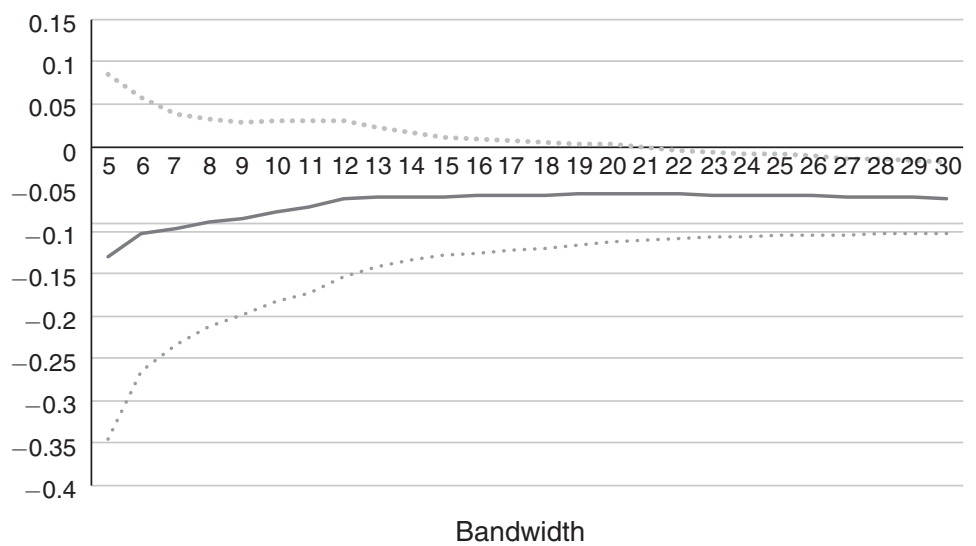

Figure 2. Employment Rate by Day of ApPlication

Notes: Panel A shows the average quarterly employment rate by each day of application and includes the estimated local linear functions superimposed on the data. Estimation results are in Table 2. The figure shows application dates within the 20-day bandwidth, from September 15 to October 4 and from October 15 to November 3. Panel B shows the regression discontinuity estimate of the difference and the estimated 95 percent confidence interval as a function of the number of days included on either side of the threshold.

and not statistically different from the result including covariates and supports the previous conclusion.

In order to consider how our results would look if measured on an annual basis, we also include in Table 2 the outcome "Ever Employed, 2010." This variable is zero if the person was not employed in each quarter of 2010, and 1 if the person had positive earnings in any quarter in 2010. Point estimates are slightly larger, at -0.056 , but are not statistically different from the quarterly outcome.

Following Lemieux and Milligan (2008), we also include a first-differenced version of the regression discontinuity design. This specification of the regression discontinuity design effectively incorporates individual fixed effects by comparing 
Panel A. Excludes October 5-October 14

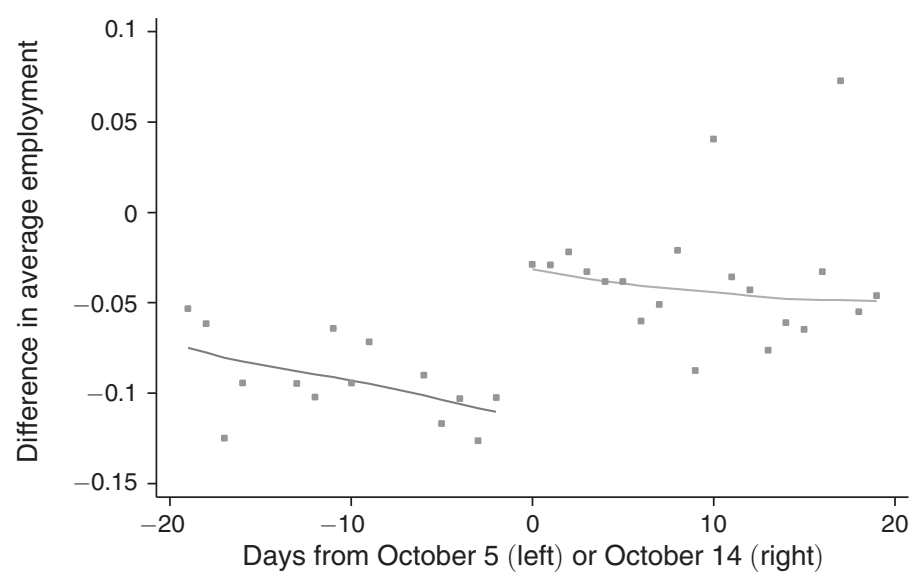

Panel B. Estimate and $95 \%$ confidence interval by bandwidth

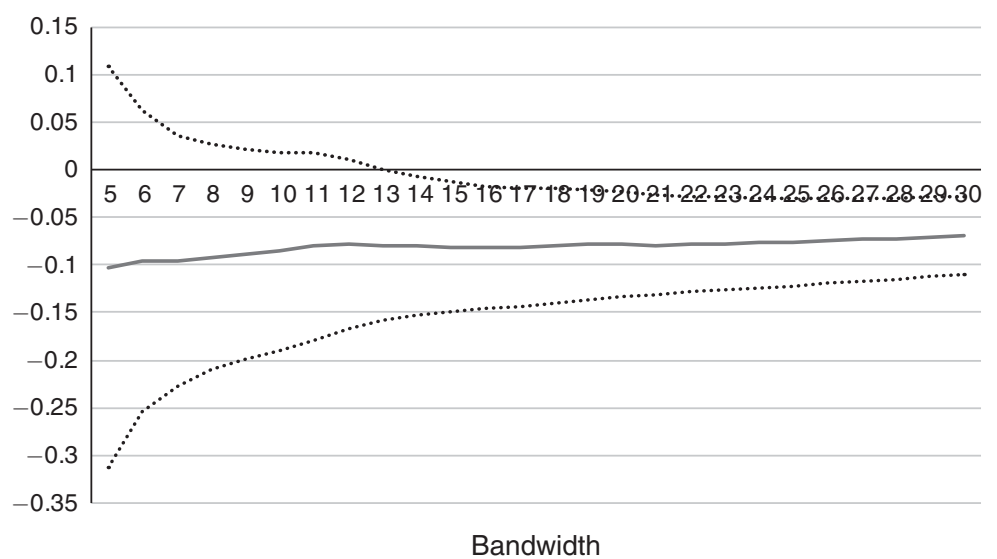

Figure 3. Employment Rate by Day of Application, First-Differenced

Notes: Panel A shows the difference in average quarterly employment rate, defined as average employment from 2009:IV to 2011:IV, average employment from 2005:I to 2009:II, by each day of application, and includes the estimated local linear functions superimposed on the data. Estimation results are in Table 2. The figure shows application dates within the 20-day bandwidth, from September 15 to October 4 and from October 15 to November 3. Panel B shows the regression discontinuity estimate of the difference and the estimated 95 percent confidence interval as a function of the number of days included on either side of the threshold.

the employment of the same individuals before and after they were or were not able to enroll into the Core Plan. We define the $y$-variable as the difference in average employment in the post-period (2009:IV to 2011:IV) and the pre-period (2005:I to 2009:II). Figure 3 illustrates the results of this specification and Table 2 lists the coefficient and standard error. The coefficient at a bandwidth of 20 days is -0.069 with a standard error of 0.028 (statistically significant at the 1 percent level), very similar to, although slightly larger than, the non-differenced results. This coefficient is robust to alternative bandwidths as shown in Figure 3. Results are the same when the pre-period is defined with a symmetric number of quarters. 
The next outcome we consider is average quarterly earnings. We note that these are net earnings; a relative reduction in earnings among those who received the insurance benefit would be expected if, for example, wage rates remained the same and Medicaid enrollees were less likely to work (as discussed above, we are unable to observe wages directly). Results for this outcome are included in Table 2. The average earnings of waitlisted applicants is higher than that of Medicaid enrollees; the results suggest that the negative earnings effect of Medicaid is just over $\$ 315$ per quarter, on average. Again, this effect includes any changes on the intensive margin (changing hours of work or wage rates) as well as the extensive margin (becoming employed). Relative to the second quarter of 2009 baseline earnings of $\$ 1,449$ for the Core Plan recipients who applied within 30 days, this is a 22 percent decline. Results from the model not including covariates are almost identical.

Figure 4 shows estimated local linear regression functions for determining the effect of public insurance participation on quarterly earnings. The dependent variable on the $y$-axis is the average total quarterly wage and salary earnings from 2009:IV to 2011:IV. We again plot the assignment variable (day of application) on the $x$-axis. Each observation is the average of the outcome for all applicants on that day, and the plot excludes the week prior to and after the cutoff day. Figure 4 shows a clear difference in average earnings between those who applied prior to the cutoff date and were able to obtain the insurance and those who applied too late, consistent with the estimates reported in Table 2. Figure 4 also includes a bandwidth robustness illustration for the estimated difference in employment; we find that the point estimate is very stable and consistent across bandwidths.

The final set of outcomes we examine is related to industry of employment. As discussed above, it is possible that the recession influenced the likelihood that those reentering the labor force changed industries, which may be more costly than a typical job transition. We consider the average quarterly probability of being employed in each of the top five industries. At the 20-day bandwidth presented in Table 3, we find a statistically significant difference for one industry. For Retail Trade, there was a 3.5 percentage point decrease in the quarterly probability that someone on the Core Plan was employed in a job in that industry relative to someone on the waitlist. This estimate is stable across bandwidths and is statistically different from zero at larger and smaller bandwidths. For Manufacturing, we find a 2 percentage point decrease in Core employment in the industry relative to the waitlist, which is not statistically significant, although it is close; however, this estimate is not stable across bandwidths; it shrinks and is statistically zero at slightly smaller and at larger bandwidths, suggesting that it may reflect random error rather than a true effect.

Relative to the nation as a whole, Wisconsin consistently has a much higher proportion of its labor force employed in Manufacturing (approximately 20 percent) and a lower proportion in Administrative and Support and Waste Management and Remediation Services (approximately 6 percent)..$^{8}$ The proportions employed in the other three top industries are very similar to the national average. Among these top five industries for our population, Manufacturing was by far the industry hardest

\footnotetext{
${ }^{8}$ Authors' tabulations from Bureau of Labor Statistics' Quarterly Census of Employment and Wages 2005-2012. Industry references are to two-digit NAICS codes.
} 
Panel A. Excludes October 5-October 14

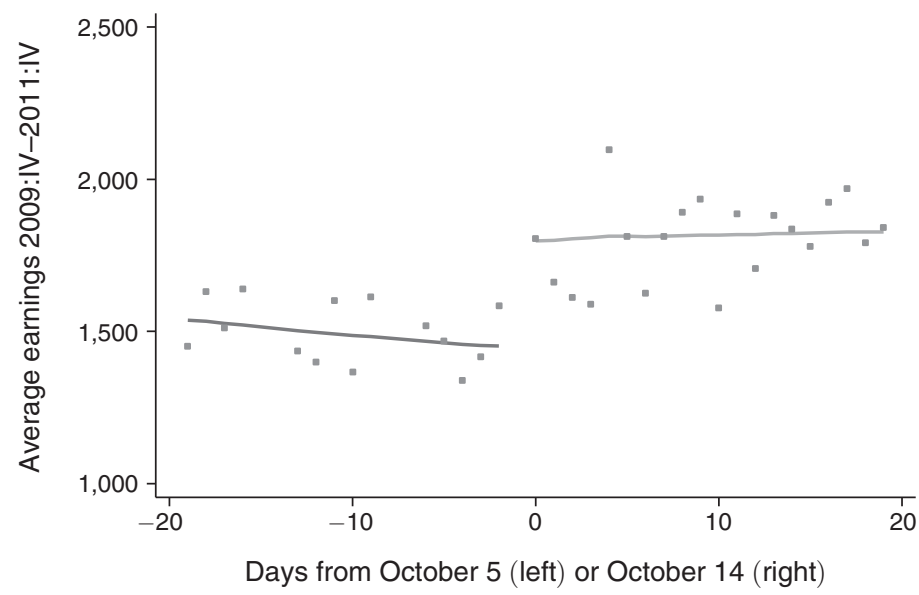

Panel B. Estimate and $95 \%$ confidence interval by bandwidth

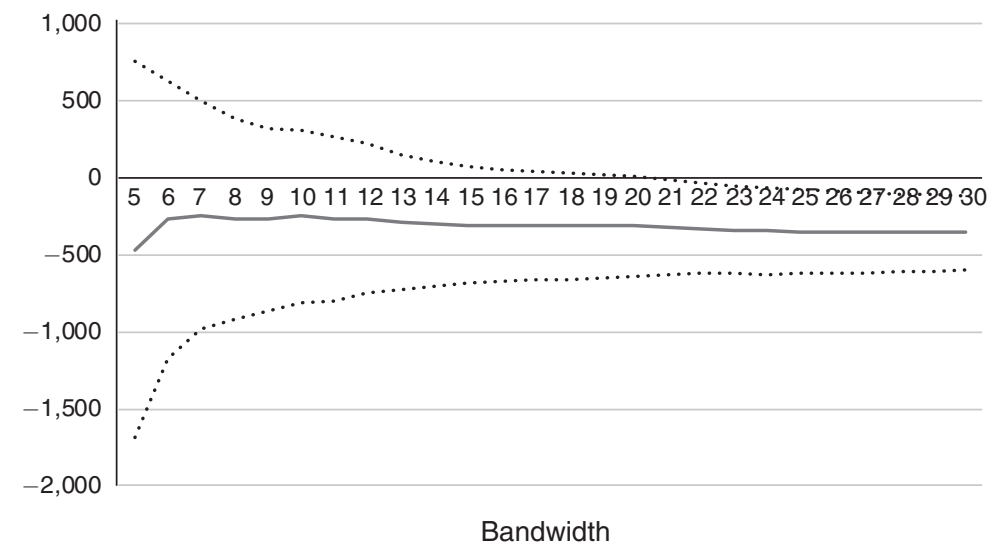

Figure 4. EARNings by Day of APPLiCATION

Notes: Panel A shows the average quarterly earnings by each day of application and includes the estimated local linear functions superimposed on the data. Estimation results are in Table 2. The figure shows application dates within the 20-day bandwidth, from September 15 to October 4 and from October 15 to November 3. Panel B shows the regression discontinuity estimate of the difference and the estimated 95 percent confidence interval as a function of the number of days included on either side of the threshold.

hit in Wisconsin during this time period (as measured by total employment); however, there is only weak evidence of differential reentry into this industry due to receipt of public health insurance. Wisconsin also saw a decline in total Retail Trade employment, and we do find that reentry into this industry was less likely for those who received public health insurance. In summary, there is some evidence that the recession may have played a role in employment dynamics as two out of the top five industries which saw the largest declines in employment were also those for which there is some evidence of differential employment by public health insurance status.

We also considered whether differential rates of employer health insurance provision might have influenced the likelihood of reentry into these industries. 
Table 3-Summary of Regression Discontinuity Results, Industry Outcomes

\begin{tabular}{|c|c|c|c|c|c|}
\hline & $\begin{array}{l}\text { Accommodation } \\
\text { and food } \\
\text { service }\end{array}$ & $\begin{array}{l}\text { Retail } \\
\text { trade }\end{array}$ & $\begin{array}{l}\text { Administrative } \\
\text { and support } \\
\text { and waste } \\
\text { management } \\
\text { and remediation }\end{array}$ & Manufacturing & $\begin{array}{l}\text { Health care } \\
\text { and social } \\
\text { assistance }\end{array}$ \\
\hline $\begin{array}{l}\text { Regression discontinuity } \\
\text { estimate }\end{array}$ & $\begin{array}{c}0.015 \\
(0.016)\end{array}$ & $\begin{array}{r}-0.035 \\
(0.016)\end{array}$ & $\begin{array}{c}0.014 \\
(0.013)\end{array}$ & $\begin{array}{r}-0.020 \\
(0.013)\end{array}$ & $\begin{array}{r}-0.008 \\
(0.015)\end{array}$ \\
\hline Female & $\begin{array}{c}0.029 \\
(0.006)\end{array}$ & $\begin{array}{c}0.032 \\
(0.006)\end{array}$ & $\begin{array}{c}-0.025 \\
(0.006)\end{array}$ & $\begin{array}{c}-0.033 \\
(0.005)\end{array}$ & $\begin{array}{c}0.085 \\
(0.006)\end{array}$ \\
\hline Earnings 2009:II (\$1,000s) & $\begin{array}{r}-0.006 \\
(0.001)\end{array}$ & $\begin{array}{r}-0.002 \\
(0.001)\end{array}$ & $\begin{array}{c}-0.003 \\
(0.001)\end{array}$ & $\begin{array}{c}0.002 \\
(0.001)\end{array}$ & $\begin{array}{c}0.005 \\
(0.002)\end{array}$ \\
\hline Employed 2009:II & $\begin{array}{c}0.102 \\
(0.008)\end{array}$ & $\begin{array}{c}0.069 \\
(0.008)\end{array}$ & $\begin{array}{c}0.044 \\
(0.008)\end{array}$ & $\begin{array}{c}0.024 \\
(0.006)\end{array}$ & $\begin{array}{c}0.045 \\
(0.009)\end{array}$ \\
\hline $\begin{array}{l}\text { Age controls (19-24 exclude } \\
\quad[24-29)\end{array}$ & $\begin{array}{l}0.01 \\
(0.014)\end{array}$ & $\begin{array}{r}-0.017 \\
(0.014)\end{array}$ & $\begin{array}{c}0.014 \\
(0.010)\end{array}$ & $\begin{array}{l}0.01 \\
(0.007)\end{array}$ & $\begin{array}{c}-0.001 \\
(0.013)\end{array}$ \\
\hline$[29-34)$ & $\begin{array}{r}-0.002 \\
(0.015)\end{array}$ & $\begin{array}{r}-0.052 \\
(0.014)\end{array}$ & $\begin{array}{c}0.022 \\
(0.011)\end{array}$ & $\begin{array}{c}0.028 \\
(0.009)\end{array}$ & $\begin{array}{r}-0.014 \\
(0.014)\end{array}$ \\
\hline$[34-39)$ & $\begin{array}{c}-0.005 \\
(0.016)\end{array}$ & $\begin{array}{r}-0.048 \\
(0.015)\end{array}$ & $\begin{array}{c}0.015 \\
(0.012)\end{array}$ & $\begin{array}{c}0.029 \\
(0.011)\end{array}$ & $\begin{array}{r}-0.018 \\
(0.015)\end{array}$ \\
\hline$[39-44)$ & $\begin{array}{c}-0.058 \\
(0.014)\end{array}$ & $\begin{array}{c}-0.044 \\
(0.016)\end{array}$ & $\begin{array}{c}0.017 \\
(0.013)\end{array}$ & $\begin{array}{c}0.035 \\
(0.012)\end{array}$ & $\begin{array}{c}-0.028 \\
(0.014)\end{array}$ \\
\hline$[44-49)$ & $\begin{array}{r}-0.037 \\
(0.014)\end{array}$ & $\begin{array}{r}-0.079 \\
(0.013)\end{array}$ & $\begin{array}{c}0.000 \\
(0.011)\end{array}$ & $\begin{array}{c}0.024 \\
(0.010)\end{array}$ & $\begin{array}{c}-0.015 \\
(0.015)\end{array}$ \\
\hline$[49-54)$ & $\begin{array}{r}-0.048 \\
(0.013)\end{array}$ & $\begin{array}{r}-0.058 \\
(0.013)\end{array}$ & $\begin{array}{c}0.013 \\
(0.011)\end{array}$ & $\begin{array}{c}0.013 \\
(0.007)\end{array}$ & $\begin{array}{r}-0.033 \\
(0.013)\end{array}$ \\
\hline$[54-59)$ & $\begin{array}{r}-0.066 \\
(0.012)\end{array}$ & $\begin{array}{r}-0.058 \\
(0.013)\end{array}$ & $\begin{array}{c}-0.002 \\
(0.011)\end{array}$ & $\begin{array}{c}0.011 \\
(0.009)\end{array}$ & $\begin{array}{r}-0.016 \\
(0.014)\end{array}$ \\
\hline$[59-64)$ & $\begin{array}{r}-0.052 \\
(0.014)\end{array}$ & $\begin{array}{r}-0.055 \\
(0.015)\end{array}$ & $\begin{array}{c}-0.025 \\
(0.011)\end{array}$ & $\begin{array}{c}0.012 \\
(0.009)\end{array}$ & $\begin{array}{r}-0.035 \\
(0.014)\end{array}$ \\
\hline $64+$ & $\begin{array}{c}-0.058 \\
(0.028)\end{array}$ & $\begin{array}{c}-0.086 \\
(0.018)\end{array}$ & $\begin{array}{r}-0.057 \\
(0.010)\end{array}$ & $\begin{array}{c}-0.002 \\
(0.013)\end{array}$ & $\begin{array}{c}-0.071 \\
(0.015)\end{array}$ \\
\hline $\begin{array}{l}\text { Application day of week } \\
\text { indicators }\end{array}$ & $\mathrm{X}$ & $\mathrm{X}$ & $\mathrm{X}$ & $\mathrm{X}$ & $\mathrm{X}$ \\
\hline $\begin{array}{l}\text { Mean of outcome variable } \\
\text { In-sample waitlist }\end{array}$ & 0.083 & 0.081 & 0.088 & 0.044 & 0.066 \\
\hline In-sample core & 0.078 & 0.064 & 0.075 & 0.04 & 0.061 \\
\hline Observations & 6,064 & 6,064 & 6,064 & 6,064 & 6,064 \\
\hline
\end{tabular}

Notes: The table displays regression discontinuity estimates of effect of getting the Core Plan, with robust standard errors in parentheses. All estimates exclude one week prior to and following the waitlist implementation. Slope coefficients for assignment variable are not included in the table. All outcomes are calculated as the fraction of quarters during which an individual was employed in that particular industry. Results are calculated at a bandwidth of 20 days. Bandwidths are defined as distance from excluded interval.

We used the 2010 Current Population Survey March Supplement to calculate the percentage of full-time workers without dependents ages 19-64 in Wisconsin who were covered by health insurance from their employer for the industry definitions closest to our top five industries. ${ }^{9}$ We found that the most likely to have

\footnotetext{
${ }^{9}$ The 2010 Current Population Survey does not use NAICS codes to classify industry.
} 
Table 4-Regression Discontinuity Results, By Subsample

\begin{tabular}{|c|c|c|c|}
\hline & $\begin{array}{l}\text { Average employment, } \\
\text { 2009:IV-2011:IV }\end{array}$ & $\begin{array}{l}\text { Average earnings, } \\
\text { 2009:IV-2011:IV }\end{array}$ & Observations \\
\hline All (benchmark) & $\begin{array}{r}-0.052 \\
(0.026)\end{array}$ & $\begin{array}{r}-315.9 \\
(150.3)\end{array}$ & 6,064 \\
\hline Women & $\begin{array}{c}-0.081 \\
(0.037)\end{array}$ & $\begin{array}{r}-540.7 \\
(224.7)\end{array}$ & 2,806 \\
\hline Men & $\begin{array}{r}-0.034 \\
(0.035)\end{array}$ & $\begin{array}{r}-147.8 \\
(206.8)\end{array}$ & 3,258 \\
\hline Age $<35$ & $\begin{array}{c}0.034 \\
(0.037)\end{array}$ & $\begin{array}{c}111.3 \\
(194.7)\end{array}$ & 2,541 \\
\hline Age $35-55$ & $\begin{array}{r}-0.102 \\
(0.042)\end{array}$ & $\begin{array}{r}-642.8 \\
(255.0)\end{array}$ & 2,367 \\
\hline Age $>55$ & $\begin{array}{r}-0.176 \\
(0.062)\end{array}$ & $\begin{array}{r}-827.2 \\
(432.2)\end{array}$ & 1,156 \\
\hline Employed at application & $\begin{array}{c}0.038 \\
(0.047)\end{array}$ & $\begin{array}{c}-55.32 \\
(284.1)\end{array}$ & 1,881 \\
\hline Unemployed at application & $\begin{array}{r}-0.070 \\
(0.032)\end{array}$ & $\begin{array}{c}-395.3 \\
(202.4)\end{array}$ & 4,183 \\
\hline High unemployment county $(>10 \%)$ & $\begin{array}{r}-0.055 \\
(0.061)\end{array}$ & $\begin{array}{c}-383.1 \\
(386.9)\end{array}$ & 1,493 \\
\hline Low unemployment county $(<=10 \%)$ & $\begin{array}{r}-0.045 \\
(0.034)\end{array}$ & $\begin{array}{r}-295.2 \\
(188.2)\end{array}$ & 4,469 \\
\hline High UE county $\times$ employed & $\begin{array}{c}0.08 \\
(-0.098)\end{array}$ & $\begin{array}{r}73.13 \\
(573.8)\end{array}$ & 463 \\
\hline High UE county $\times$ unemployed & $\begin{array}{l}-0.06 \\
(0.063)\end{array}$ & $\begin{array}{r}-391.4 \\
(505.2)\end{array}$ & 1,030 \\
\hline Low UE county $\times$ employed & $\begin{array}{c}-0.008 \\
(-0.051)\end{array}$ & $\begin{array}{c}-223.3 \\
(324.5)\end{array}$ & 1,383 \\
\hline Low UE county $\times$ unemployed & $\begin{array}{r}-0.074 \\
(0.037)\end{array}$ & $\begin{array}{r}-394.5 \\
(214.2)\end{array}$ & 3,086 \\
\hline
\end{tabular}

Notes: The table displays regression discontinuity estimates of effect of getting the Core Plan, with robust standard errors in parentheses. All results calculated at a bandwidth of 20 days, for specification excluding October 5October 14, and includes as controls the covariates in Table 2 not used as outcomes (age controls linear).

health insurance from their employer were, in order, Manufacturing (79 percent), Education, Health, and Social Services (70 percent), Administrative and Waste Management (67 percent), Wholesale/Retail Trade (59 percent), and Arts, Accommodation, and Food Services (44 percent). There is no evidence that workers who did not receive insurance were more motivated to get a job in an industry more likely to provide insurance.

\section{B. Subgroup Analysis}

Table 4 reports the results of the regression discontinuity estimation for employment, and earnings for several splits of the sample: by sex, by age, by employment status prior to application, and by local unemployment rate. The table includes only the specification that excludes October 5 to October 14 applications and all results are reported at a bandwidth of 20 days. 
When we divide the sample by sex, we find that point estimates are slightly larger for women $(-8.1$ percentage points) than for men $(-3.4$ percentage points). For age, we separated the sample into three groups, those less than 35 , those $35-55$, and those older than 55. Split this way, there are clear and important differences in the estimated employment effect by age. The effect is approximately twice as large as the average for those between 35 and 55 years old ( -10.2 percentage points), and more than three times as large as average for those over the age of $55(-17.6$ percentage points). For those under 35, effects are weakly positive (meaning that employment among Core Plan enrollees increased relative to those on the waitlist), although these are not statistically different from zero. These results are consistent with an early retirement story for older workers who may have found it more difficult to obtain a new job, and lost a valuable incentive to search when they obtained health insurance through the Core Plan. In contrast, younger workers on the waitlist may have chosen to search longer for a job that provided benefits, since they did not have insurance available to them; however, we cannot know, with the data available to us, whether or not jobs provided benefits.

The point estimate for those who were not employed at the time of application to the Core Plan is -7 percentage points, while the coefficient is positive although not statistically significant for those who were employed at the time of application. While effect sizes are not particularly different for the average applicant living in a high versus low unemployment county (split at 10 percent, the seventy-fifth percentile unemployment rate weighted by individual), in case of potential interactions between the local labor market and an applicant's prior employment status, we also looked at the subsample of employed and non-employed applicants who were living in high or low unemployment counties at the time of application. These results are also shown in Table 4. There are no differences across the Core/waitlist for the employed in low unemployment counties, but for the non-employed in low unemployment counties there is a large and statistically significant difference: Core recipients were 7.4 percentage points less likely to be employed in the post-period on average. For employed workers in high unemployment counties, the coefficient is large and positive but not statistically different from zero, and for the unemployed workers in high unemployment counties, the effect is similar in magnitude to the average. These effects are all stable across bandwidths and more precisely estimated at larger bandwidths.

On average, we calculated that employed workers had very similar employment rates in the post-period if they were in low unemployment (68.8 percent) or in high unemployment (69.0 percent) counties, while the non-employed workers had slightly higher employment rates in low unemployment counties (26.6 percent) than in high unemployment counties (25.8 percent). Taken together, these results support the idea that there is no effect on labor supply for the non-employed in bad labor markets; they may find it difficult to get a job regardless of whether they have health insurance or not; while for the non-employed in low unemployment counties, there are enough jobs available for the health insurance to make a difference in marginal incentives to participate in the labor market. Employed workers in high unemployment counties were also more likely to lose their job in the post-period than those in low unemployment counties, again giving the health insurance a chance to affect marginal incentives for the unemployed. 


\section{Regression Discontinuity Specification Checks}

The potential for bias exists if, for example, an unobserved characteristic such as "preference for health insurance" is driving exact application timing. We expect that those with the strongest preference for insurance would have signed up immediately upon program availability, and there were indeed a large number of signups in June and July. These are not included in any of the RD specifications since they are outside of the bandwidths. The preference is likely to be decreasing with the time of program availability, but for the preference for health insurance to bias the RD results, it would need to be different across the cutoff date. One possibility is that waitlisted applicants are differentially less concerned about qualifying for the program, and so they might be less inclined to keep incomes low in order to continue to stay income-eligible for the program. ${ }^{10}$ Since we find that waitlisted applicants are more likely to be employed, this type of bias would suggest we are finding this too often, overstating the result. On the other hand, waitlisted applicants might be procrastinators, and perhaps thus lower quality workers, which might lead us to think the results are understated. These differences in behavior must be due to inherent differences in the applicants' preferences in order to bias the results; differences in behavior due to getting or not getting the insurance are part of the treatment effect. While we are unable to test for violations of the identification assumption directly, we provide several validity checks in this section in addition to those included as part of the results discussed above (bandwidth robustness and exclusion of covariates in the regressions).

One standard check is to test whether the density of observations as a function of the assignment variable is continuous through the discontinuity threshold. While this check is neither necessary nor sufficient for a valid regression discontinuity design (McCrary 2008), it can be suggestive as to whether the identifying assumption is violated. As discussed above, the surge in applications in the last week means that the density of observations in our data (shown in online Appendix Figure 1) is not continuous through October 9. As explained, we take the approach of leaving out the data just prior to and after October 9, assuming that applications were fully displaced from the week prior. We also estimate the main specifications including all applications and by leaving out just the announcement week. We include illustrations of these specifications as online Appendix Figure 2 (employment outcome) and online Appendix Figure 3 (earnings outcome) and report the results in online Appendix Table 1. Results are the same direction as the main results, but are larger, and the inclusion of covariates makes a large difference in the size of the estimate, suggesting that these specifications are not preferred.

\footnotetext{
${ }^{10}$ Another possibility is that the distribution mechanism itself could influence the labor supply decisions of affected participants. If, alternatively, the waitlist participants we use as a control group for Medicaid recipients are themselves constrained by the waitlist because, for example, they believe they need to remain eligible for the program in order to eventually receive it, this would bias against us finding any effects. Most of the literature on waiting lists relates to allocation of medical care. Propper $(1990,1995)$ points out that there are costs to using waiting lists as mechanisms for medical care allocation in the United Kingdom and estimates these costs using contingent valuation. Globerman (1991) discusses the potential for decreases in productivity due to waiting times. These studies do not examine a random allocation mechanism as an alternative choice. Cullis, Jones, and Propper (2000) provide a general treatment of the theoretical and empirical literature on waiting lists for health care services.
} 
Online Appendix Table 2 reports the results of testing whether predetermined characteristics of the applicants were continuous throughout application days. In our preferred specification, we find no differences in the proportion female, prior earnings, prior employment, or prior industry across the date threshold. Online Appendix Table 2 also reports these tests for the alternate date specifications for the non-industry covariates. We do find a small but statistically significant difference in age: waitlisted applicants were slightly younger than Core recipients. This difference in age may be a bias concern if employers are more willing to hire younger workers. However, at a minimum, results are not sensitive to how age is modeled. For example, in the main employment regressions for the RD analysis, linear age controls result in an RD coefficient of -0.052 (0.026), including age and age squared results in a coefficient of $-0.053(0.026)$; with three broad age bands, as in our split sample analysis from Table 4 results in a coefficient of $-0.054(0.026)$; with indicators for each year of age, $-0.056(0.026)$.

While we are not able to test directly for any differences in preferences for insurance since we do not have access to data on health care usage for the full sample of waitlisted applicants, for a subgroup of applicants living in rural north central Wisconsin and receiving the majority of their health care services from a dominant provider group, we are able to consider health care outcomes. We use the same regression discontinuity design from this study to look at how public insurance affects usage of health care and compare health care usage in the pre-period among the waitlisted and enrolled applicants (Burns et al. 2014). We find no differences among those who applied just before and just after the waitlist implementation for two years of prior emergency department use, inpatient hospitalizations, outpatient visits, mental health visits, or preventive care visits. This finding supports the validity of the design.

In addition, all individuals who enrolled into the BadgerCare Plus Core Plan were administered a health needs assessment. Comparing individual self-reports on rates of smoking and rates of chronic illness by week of application, we find no evidence that individuals who applied in the weeks just proceeding or during the announcement week (the week of October fifth) differed from those who applied in earlier weeks (see online Appendix Table 3). This finding also supports the validity of the design by showing there is no apparent trend in the self-reported health needs by application date for those who received the Core Plan (although no data exist for those on the waitlist).

If the employment results reflect inherent differences between those who applied earlier and later and not those driven by the timing of the waitlist implementation, one might expect that using the exact threshold is not important, and similar results would be found when treating other dates as the threshold date. To check this, we perform placebo date tests for the preferred specification as well as for the alternate inclusions of observations between announcement and waitlist implementation. Online Appendix Table 4 reports the results of these tests. In the preferred specification, we do not find any evidence that using an alternate date would result in similar conclusions; there is no pattern of statistically significant differences between the redefined "waitlist" and "Core" groups when treating these placebo dates as the true threshold, supporting the validity of the design. 
In addition to our outcome measure that averages all available post-period quarters, we have estimated specifications with both annual outcomes (probability ever employed in a year) and quarterly outcomes (probability of employment in every quarter prior to and following the timing of insurance receipt); the annual specification is reported in Table 2 and was discussed above, and the quarterly outcomes are summarized visually in Figure 1; there were no statistically significant differences in any quarter prior to the fourth quarter of 2009; afterwards, we find a statistically significant effect of similar magnitude in almost every quarter covered by our data. Therefore, the results do not seem to be sensitive to the definition of the outcome variable.

Even considering this evidence supporting the design, it remains possible that the average person applying just after the waitlist implementation differs from the average person applying just before, biasing the RD estimates. As displayed in online Appendix Figure 1, the announcement substantially changes the number of applicants, with a surge in applications of over 6,000 during the announcement week and a decrease in applications following the waitlist implementation. This suggests that some individuals were induced to apply either earlier than they otherwise would have (or they may never have applied). Some would have always applied that week. During the month prior to announcement, applications averaged 1,300 per week; the following month averages 840, suggesting approximately 460 applications per week "missing" or that 30 percent of the total increase in applications would have applied within the next 30 days. There is no way to observationally differentiate between these potential types of applicants. For this reason, we provide estimates in the next section using an alternative empirical approach that relies on different identifying assumptions as a complement to the RD analysis.

\section{Difference-in-Differences Estimation}

We now turn to an alternative empirical model to further support the robustness of our results. Because of the announcement issue, the regression discontinuity design is potentially imperfect; the average person applying just after the waitlist was implemented could be different from the average person applying just before the waitlist, which would bias our estimates. In contrast, a difference-in-differences model requires an alternative assumption: that underlying trends in the outcome variables between those who did and did not get the Core Plan would have been similar in the absence of the Core Plan. We also include propensity score weighted versions of this model (Heckman, Ichimura, and Todd 1997). Combining the difference-in-differences model with propensity score matching allows us to further adjust the comparability of the two groups based on past labor market history and other observable characteristics. If there were no differences between waitlist applicants and enrolled applicants, the regression discontinuity and difference-in-differences approaches would be equally valid. We think the ability to assess the robustness of the results across these methods provides more convincing evidence than implementing either approach on its own.

The difference-in-differences model assumes parallel trends in outcomes between the Core and waitlist groups and takes full advantage of the panel nature of the employment and earnings data. The propensity score weighted difference-in-differences 
design involves making the Core and waitlist groups as comparable as possible based on observable characteristics. The most important difference with propensity score weighting relative to the regression discontinuity approach is the assumption required for identification: we must assume that conditional on observables included in the propensity score, there was no selection on time-varying characteristics in the date of application (Smith and Todd 2005). We include individual fixed effects in all difference-in-differences specifications so that any within-individual, time-invariant unobservable characteristics (such as a risk aversion parameter, preexisting health condition, or preference for health insurance) are differenced out of the estimates.

A rich methodological literature establishes the conditions under which the use of propensity scores is appropriate in examining labor market outcomes (examples include Card and Sullivan 1988; Dehejia and Wahba 1999; Deheja and Wahba 2002; Heckman et al. 1996; Heckman, Ichimura, and Todd 1997; Heckman and Smith 1999; and Smith and Todd 2005). A key finding from this body of work is that the underlying assumptions of propensity score methods are best met by including data on lagged labor market outcomes; indeed, lagged labor market measures have been found to be the single most important set of matching variables. We have access to historical UI data, which we use to construct such measures for the study sample. Moreover, our data meet the other key conditions established in the aforementioned methodological literature: matched treatments and controls are drawn from the same geographical labor market and their respective labor market outcomes are measured in the same way (Heckman et al. 1996; Heckman, Ichimura, and Todd 1997). ${ }^{11}$

We provide estimates for two samples: an "all applications" sample, which includes application dates from the beginning of the Core program until an equal interval after the waitlist cutoff date (117 days), and we embed our regression discontinuity framework within the propensity score approach and estimate these models on a second sample restricting to applications within 30 days of the cutoff date. The sample always consists of a balanced panel of all applicants within the two windows. The number of observations per person is therefore 28, reflecting seven years of quarterly data. Unlike in the regression discontinuity models, we include applications that occurred between waitlist announcement and implementation in these models, and rely on the fixed effects and matching to adjust for any changes in applicant types.

In particular, we estimate the following model:

$$
Y_{i t}=\beta_{0}+\beta_{1} \text { Post }_{i t}+\beta_{2} \text { Core }_{i t}+\beta_{3} \text { Post } \times \text { Core }_{i t}+\varphi_{i}+\varepsilon_{i t},
$$

where $Y_{i t}$ is an indicator for positive employment or total earnings for individual $i$ in quarter $t$; Post $_{i t}$ is an indicator for 2009:III to 2011:IV; Core $_{i t}$ is an indicator for the individual enrolled into the Core Plan; and $\varphi_{i}$ is an individual fixed effect.

We cluster standard errors at the individual level. For specifications that include propensity score adjustments, we estimate the propensity score using a probit with controls for quarterly employment for each quarter from 2005:I to 2009:II, quarterly

\footnotetext{
${ }^{11}$ Also of note is a German study that finds that propensity score models including lagged labor market measures and a set of demographic covariates similar to our own perform just as well as models augmented with additional person-level measures such as personality traits and motivation (Biewen et al. 2014).
} 
earnings in each quarter from 2005:I to 2009:II, age, sex, and county of residence. We then construct a propensity score weight for each control observation (waitlisted applicants) using an Epanechnikov kernel weight and implement the estimation using these propensity score weights (Leuven and Sianesi 2003).

Table 5 reports the results from the difference-in-differences models. The models are based on equation (2) and all specifications include individual fixed effects with standard errors clustered at the individual level. These models thus difference out any time-invariant observable and unobservable individual characteristics, such as a static degree of risk aversion or preference for insurance. The coefficient should be interpreted as the change in average quarterly employment rates (or average quarterly earnings) over the "post" period (2009:IV to 2011:IV) from the average in the "pre" period (2005:I to 2009:II) for those enrolled in the Core Plan relative to those waitlisted. A positive coefficient means that Core recipients were more likely to be employed than waitlisted applicants. We note in particular that the estimation samples do include those individuals who applied between the announcement of the waitlist and its implementation.

The results of the difference-in-differences models, shown in the first column of Table 5, indicate a relative decline in the average employment rate of 5.3 percentage points for those with public insurance; these results are statistically significant. When we restrict the sample to those who applied in September and October 2009, the estimated relative reduction in employment rates remains very similar-5.0 percentage points - and remains statistically significant. These results are almost identical to the regression discontinuity results. Panel A of Figure 1 shows that pre-period and post-period trends in average employment for those who applied within 30 days appear parallel, and although not shown, the graph for the all applications sample is almost identical. In panel B of Table 5, we provide the results for treating average quarterly earnings as the outcome variable. The earnings outcomes suggest lower quarterly earnings for the Core recipients of \$74 and \$204 for the all applications and within-30-days samples, respectively.

Table 5 also includes the results from the propensity score weighted versions of these models in column 2 . The propensity score predicts the probability of receiving Core conditional on past labor market history as well as other observable characteristics. Illustrations of both the unadjusted and propensity score adjusted earnings for each quarter for the Core recipients and waitlisted applicants who applied within 30 days of the waitlist implementation are shown in Figure 1. The figure makes clear that the effect of the matching is to eliminate any pre-period differences in average labor supply, so that any differences in outcomes are solely attributable to the post-period. Online Appendix Table 5 shows the means for the Core and waitlist groups for both the all applicants and the applied within 30 days groups after matching. It also provides the results of a standardized bias test, which shows the difference in means as a percentage of the square root of the average of the sample variances in both groups, and the results of a two-sample $t$-test for differences in the means. We can conclude that the matching process is successful; the sample that applied within 30 days of October 9 is particularly well matched. We provide the results of the propensity score estimation itself in online Appendix Table 6, and online Appendix Figure 4 illustrates the common support across applicant groups. 
Table 5-Summary of Difference-In-Differences Results

\begin{tabular}{|c|c|c|}
\hline & (1) & (2) \\
\hline \multicolumn{3}{|c|}{$\begin{array}{l}\text { Panel A. Average quarterly employment } \\
\text { All application dates }\end{array}$} \\
\hline Post $\times$ core plan & $\begin{array}{r}-0.053 \\
(0.004)\end{array}$ & $\begin{array}{r}-0.035 \\
(0.004)\end{array}$ \\
\hline PS weighted & & $\mathrm{X}$ \\
\hline Observations & $1,587,264$ & $1,563,772$ \\
\hline Individuals & 56,688 & 55,849 \\
\hline \multicolumn{3}{|c|}{ Within 30 days of October 9} \\
\hline Post $\times$ core plan & $\begin{array}{r}-0.050 \\
(0.007)\end{array}$ & $\begin{array}{c}-0.031 \\
(0.008)\end{array}$ \\
\hline PS weighted & & $\mathrm{X}$ \\
\hline Observations & 389,872 & 383,600 \\
\hline Individuals & 13,924 & 13,700 \\
\hline \multicolumn{3}{|c|}{$\begin{array}{l}\text { Panel B. Average quarterly earnings } \\
\text { All application dates }\end{array}$} \\
\hline Post $\times$ core plan & $\begin{array}{r}-73.61 \\
(24.91)\end{array}$ & $\begin{array}{l}-50.7 \\
(24.21)\end{array}$ \\
\hline PS weighted & & $\mathrm{X}$ \\
\hline Observations & $1,587,264$ & $1,563,772$ \\
\hline Individuals & 56,688 & 55,849 \\
\hline \multicolumn{3}{|c|}{ Within 30 days of October 9} \\
\hline Post $\times$ core plan & $\begin{array}{l}-204.4 \\
(50.87)\end{array}$ & $\begin{array}{r}-103.1 \\
(51.85)\end{array}$ \\
\hline PS weighted & & $\mathrm{X}$ \\
\hline Observations & 389,872 & 383,600 \\
\hline Individuals & 13,924 & 13,700 \\
\hline
\end{tabular}

Notes: The "pre" period includes 2005:I to 2009:II and the "post" period includes 2009:IV to 2011:IV. All estimates include individual fixed effects and standard errors are clustered at the individual level. Observations with application dates less than the absolute value of the difference from the first to last Core application (June 15, 2009 to October 9, 2009) are included in the "All application dates" specifications (waitlist applications after February 3, 2010 are excluded).

When we estimate the models using our propensity score weighted sample, the employment results are slightly smaller, with a difference of 3.5 percentage points for the all applicants sample and 3.1 percentage points for the within 30 days sample, but remain statistically significant. Earnings results are also slightly smaller at $\$ 51$ and $\$ 103$ for the all applicants and within 30 days samples, respectively. While slightly smaller in magnitude than the unadjusted difference in differences and regression discontinuity results, these estimates also support the conclusion that public health insurance reduces labor supply.

All of the difference-in-differences results are robust to the inclusion of linear and quadratic time trends and quarter fixed effects, as well as linear and quadratic time trends that vary by county and county-specific quarterly shocks (modeled as county by quarter fixed effects). They are also robust to the inclusion of a full set of indicators for the number of quarters to application, addressing the possibility that the quarter in which application occurred could have been different for a subset of 
Core recipients and waitlisted applicants. These specifications are available upon request from the authors.

\section{Discussion and Conclusion}

In this study, we examine the labor supply effects of publicly provided health insurance for low income adults without dependent children. Our findings suggest public insurance has a disincentive effect on the labor supply of low income childless adults. The sizes of our estimated effects are modest, indicating a relative difference of 5.2 percentage points in our preferred regression discontinuity specification. Among a population in which less than half of enrollees had any positive earnings in the quarter prior to application, these are economically meaningful effects: relative to the baseline 44.7 percent employment rate, the point estimate represents a 12 percent relative reduction. The 95 percent confidence intervals for these results allow us to rule out the possibility that public health insurance enrollment increases labor supply as well as the chance that it causes large decreases in labor supply on average. Our evidence suggests the net effect on earnings (including those who lost or changed jobs) was a reduction of just more than $\$ 300$ per quarter. We note that as both the Core recipients and waitlisted applicants were increasing their labor supply on average throughout the majority of the post-application period, these results should be interpreted not as the Core recipients actively resigning from current jobs but as a decreased likelihood of returning to the labor market.

There are several caveats to our results. First, while we find negative employment effects using two different and complementary methods relying upon different identifying assumptions and across a variety of specifications, our identification strategies are not perfect. For example, even adjusting for observable differences between the Core Plan enrollees and the waitlisted applicants using the rich earnings and employment histories available in the UI data and employing both fixed effects and difference-in-differences (which net out any fixed unobserved differences) does not preclude the existence of time-varying unobserved differences between the two samples. Moreover, the waitlist was announced precipitously and may have resulted in unobservable differences between those who were willing to apply before and after; we do find differences at the cutoff discontinuity in the age of the applicants between those waitlisted and those enrolled, which may indicate a violation of the RD identifying assumption. While these age differences are small and the estimated effects change little when we control for age in the RD models, the concern remains.

A second caveat, as discussed above, is that extrapolating from the Wisconsin Core Plan for childless adults to an expansion of Medicaid to childless adults in general may not be possible. The two programs differ in an important way: Medicaid is an entitlement while the Core Plan was not. Since new enrollment into the Core Plan was ended on October 9, 2009, any Core Plan member who left the plan (perhaps as a result of gaining health insurance through a new employer), would not be able to go back on the plan should he or she subsequently lose private insurance. This would not be the case with Medicaid; individuals would be free to exit and reenter the program as their eligibility changes. The fact that the Core Plan is not an entitlement could have had a "lock-in" effect on enrollees, exacerbating any employment 
disincentive relative to Medicaid. However, the waitlist itself may have provided a disincentive to work if waitlisted applicants were trying to stay under the income threshold to remain qualified, and waitlisted applicants eventually had access to a stop-gap program. Although only a small percentage of them took it up, its existence would provide a work disincentive as well, and reduce the relative employment disincentive of public insurance.

As with other studies utilizing unemployment insurance records, we do not observe transitions into and out of self-employment. As we cannot differentiate between self-employment and being out of the labor force, we could be overstating the association between public insurance eligibility and labor market attachment. Using auxiliary data from the American Community Survey, we explore trends in self-employment among the target population of interest over the study period in order to deduce the potential magnitude and direction of any resulting bias from mislabeling. This analysis is included in the online Appendix. While we find no evidence that the inability to identify self-employed members of our sample is biasing us towards finding a reduction in labor supply, we of course cannot test for it directly in our own data. In addition, we are unable to observe the employment of individuals who move out of state during the study period; this is likely to bias against finding any effect if those who did not receive insurance are more likely to move, as these individuals would appear to be non-employed in our administrative data.

Our estimates of the labor supply disincentive of public insurance are larger than those found by Baicker et al. (2014), which estimated that Medicaid enrollment led to a 1.6 percentage point reduction in employment in Oregon, and substantially smaller than those found by Garthwaite, Gross, and Notowidigdo (2014), which found that Medicaid disenrollment led to a 60 percent increase in employment in Tennessee. One possible explanation for the variation in estimates is an interaction between the programs and the business cycle. Our findings reported in Table 4 show that the labor supply response was greater among individuals who were not employed at the time of their application to the Core plan and that the strongest response came from those living in counties with relatively low unemployment rates. These findings suggest that part of the reason for the larger estimates in Garthwaite, Gross, and Notowidigdo (2014) and for the smaller estimates in Baicker et al. (2014) may be differing levels of economic activity across years and states. For example, the statewide unemployment rate was 5.6 percent in Tennessee in 2005; it was 11.1 percent in Oregon in 2009; and it was 8.5 percent in Wisconsin in 2010.12

An important question is how the recent Medicaid expansion enacted by many states under the ACA will affect the labor supply of newly eligible adults. Given the evidence presented in this paper, we believe it would be prudent for policymakers to be prepared to observe a reduction in labor supply among childless adults affected by the Medicaid expansion under the Affordable Care Act. Reductions in employment of roughly 5.2 percentage points (our best estimate) would be sufficiently large

\footnotetext{
${ }^{12}$ Another source of difference between the Oregon, Tennessee, and Wisconsin Medicaid programs was that the income eligibility thresholds differed across these states. It is possible that these differences contribute to the differences in the estimated labor supply effects of the programs.
} 
to be noticeable economy wide. For example, if 21.3 million additional adults gain Medicaid coverage following the ACA expansions, then approximately 1.1 million fewer individuals will be employed as a result of the labor supply response. This aggregate response would be equivalent to roughly a 0.8 percent drop in the number of individuals employed in 2014.

It is important to note that the availability of generous tax credits for the purchase of insurance coverage in state-based or federally-facilitated health insurance marketplaces under the ACA changes the consequences for becoming ineligible for Medicaid substantially. In the states that have expanded adult Medicaid eligibility to 138 percent FPL under the ACA as well as in Wisconsin, which expanded eligibility to 100 percent FPL, individuals become eligible for the ACA's Advanced Premium Tax Credits (APTCs) at the same income threshold at which they become ineligible for Medicaid. While it is unclear what the total effect of the APTCs will be on labor supply (as they are reduced with family income), it is likely that they will mitigate the negative labor supply effect of Medicaid. Of course, since many states have not yet expanded Medicaid under the ACA, estimates of the labor supply effects of adult Medicaid enrollment will remain highly relevant.

\section{REFERENCES}

Baicker, Katherine, and Amitabh Chandra. 2006. "The Labor Market Effects of Rising Health Insurance Premiums." Journal of Labor Economics 24 (3): 609-34.

- Baicker, Katherine, Amy Finkelstein, Jae Song, and Sarah Taubman. 2014. "The Impact of Medicaid on Labor Market Activity and Program Participation: Evidence from the Oregon Health Insurance Experiment." American Economic Review 104 (5): 322-28.

-Barreca, Alan I., Jason M. Lindo, and Glen R. Waddell. 2016. "Heaping-Induced Bias in Regression-Discontinuity Designs." Economic Inquiry 54 (1): 268-93.

- Biewen, Martin, Bernd Fitzenberger, Aderonke Osikominu, and Marie Paul. 2014. "The Effectiveness of Public Sponsored Training Revisited: The Importance of Data and Methodological Choices." Journal of Labor Economics 32 (4): 837-97.

Bound, John. 1989. "The Health and Earnings of Rejected Disability Insurance Applicants." American Economic Review 79 (3): 482-503.

-Boyle, Melissa A., and Joanna N. Lahey. 2010. "Health insurance and the labor supply decisions of older workers: Evidence from a US Department of Veterans Affairs expansion." Journal of Public Economics 94 (7): 467-78.

-Burns, Marguerite E., Laura Dague, Thomas DeLeire, Mary Dorsch, Donna Friedsam, Lindsey Jeanne Leininger, Gaston Palmucci, et al. 2014. "The Effects of Expanding Public Insurance to Rural Low-Income Childless Adults." Health Services Research 49 (S2): 2173-87.

-Card, David, and Daniel Sullivan. 1988. "Measuring the Effect of Subsidized Training Programs on Movements in and out of Employment." Econometrica 56 (3): 497-530.

Chen, Susan, and Wilbert van der Klaauw. 2008. "The work disincentive effects of the disability insurance program in the 1990s." Journal of Econometrics 142 (2): 757-84.

Congressional Budget Office. 2014. "Appendix C: Labor Market Effects of the Affordable Care Act: Updated Estimates." In The Budget and Economic Outlook: 2014 to 2024, 117-27. Washington, DC: Congressional Budget Office.

Cullis, John G., Philip R. Jones, and Carol Propper. 2000. "Waiting lists and medical treatment: Analysis and policies." In Handbook of Health Economics, Vol. 1B, edited by Anthony J. Culyer and Joseph P. Newhouse, 1201-49. Amsterdam: North-Holland.

Dague, Laura, Thomas DeLeire, and Lindsey Leininger. 2017. "The Effect of Public Insurance Coverage for Childless Adults on Labor Supply: Dataset." American Economic Journal: Economic Policy. https://doi.org/10.1257/pol.20150059.

Dave, Dhaval, Sandra L. Decker, Robert Kaestner, and Kosali I. Simon. 2015. "The Effect of Medicaid Expansions in the Late 1980s and Early 1990s on the Labor Supply of Pregnant Women." American Journal of Health Economics 1 (2): 165-93. 
Dehejia, Rajeev H., and Sadek Wahba. 1999. "Causal Effects in Nonexperimental Studies: Reevaluating the Evaluation of Training Programs." Journal of the American Statistical Association 94 (448): 1053-62.

Dehejia, Rajeev H., and Sadek Wahba. 2002. "Propensity Score-Matching Methods for Nonexperimental Causal Studies." Review of Economics and Statistics 84 (1): 151-61.

-Eissa, Nada, and Hilary Williamson Hoynes. 2004. "Taxes and the labor market participation of married couples: The earned income tax credit." Journal of Public Economics 88 (9): 1931-58.

Ellwood, David T., and E. Kathleen Adams. 1990. "Medicaid mysteries: Transitional benefits, Medicaid coverage, and welfare exits." Health Care Financing Review (Supplement): 119-31.

-Fairlie, Robert W., Kanika Kapur, and Susan Gates. 2011. "Is employer-based health insurance a barrier to entrepreneurship?" Journal of Health Economics 30 (1): 146-62.

-French, Eric, and John Bailey Jones. 2011. "The Effects of Health Insurance and Self-Insurance on Retirement Behavior." Econometrica 79 (3): 693-732.

-French, Eric, and Jae Song. 2014. "The Effect of Disability Insurance Receipt on Labor Supply." American Economic Journal: Economic Policy 6 (2): 291-337.

-Garthwaite, Craig, Tal Gross, and Matthew J. Notowidigdo. 2014. "Public Health Insurance, Labor Supply, and Employment Lock." Quarterly Journal of Economics 129 (2): 653-96.

-Globerman, Steven. 1991. "A Policy Analysis of Hospital Waiting Lists." Journal of Policy Analysis and Management 10 (2): 247-62.

-Gruber, Jonathan, and Jeffrey D. Kubik. 1997. "Disability insurance rejection rates and the labor supply of older workers." Journal of Public Economics 64 (1): 1-23.

Ham, John, and Lara Shore-Sheppard. 2001. "The Impact of Public Health Insurance on Labor Market Transitions." Williams College Department of Economics Working Paper 2001-02.

Ham, John C., and Lara D. Shore-Sheppard. 2005. "Did Expanding Medicaid Affect Welfare Participation?" Industrial and Labor Relations Review 58 (3): 452-70.

- Hamersma, Sarah. 2013. "The Effects of Medicaid Earnings Limits on Earnings Growth among Poor Workers." B.E. Journal of Economic Analysis and Policy 13 (2): 887-919.

-Hamersma, Sarah, and Matthew Kim. 2009. "The effect of parental Medicaid expansions on job mobility." Journal of Health Economics 28 (4): 761-70.

-Heckman, James J., Hidehiko Ichimura, Jeffrey Smith, and Petra Todd. 1996. "Sources of selection bias in evaluating social programs: An interpretation of conventional measures and evidence on the effectiveness of matching as a program evaluation method." Proceedings of the National Academy of Sciences 93 (23): 13416-20.

Heckman, James J., Hidehiko Ichimura, and Petra E. Todd. 1997. "Matching as an Econometric Evaluation Estimator: Evidence from Evaluating a Job Training Programme." Review of Economic Studies 64 (4): 605-54.

-Heckman, James J., and Jeffrey A. Smith. 1999. "The Pre-programme Earnings Dip and the Determinants of Participation in a Social Programme: Implications for Simple Programme Evaluation Strategies." Economic Journal 109 (457): 313-48.

-Holtz-Eakin, Douglas, John R. Penrod, and Harvey S. Rosen. 1996. "Health insurance and the supply of entrepreneurs." Journal of Public Economics 62 (1-2): 209-35.

Hoynes, Hilary Williamson, and Diane Whitmore Schanzenbach. 2012. "Work incentives and the Food Stamp Program.” Journal of Public Economics 96 (1): 151-62.

-Jacob, Brian A., and Jens Ludwig. 2012. "The Effects of Housing Assistance on Labor Supply: Evidence from a Voucher Lottery." American Economic Review 102 (1): 272-304.

-Lee, David S., and Thomas Lemieux. 2010. "Regression Discontinuity Designs in Economics.” Journal of Economic Literature 48 (2): 281-355.

Lemieux, Thomas, and Kevin Milligan. 2008. "Incentive effects of social assistance: A regression discontinuity approach." Journal of Econometrics 142 (2): 807-28.

Leuven, E., and B. Sianesi. 2003. "PSMATCH2: Stata module to perform full Mahalanobis and propensity score matching, common support graphing, and covariate imbalance testing." http://ideas. repec.org/c/boc/bocode/s432001.html (accessed October 22, 2014).

Lombard, K. V. 2001. "Female self-employment and demand for flexible, nonstandard work schedules." Economic Inquiry 39 (2): 214-37.

-Maestas, Nicole, Kathleen J. Mullen, and Alexander Strand. 2013. "Does Disability Insurance Receipt Discourage Work? Using Examiner Assignment to Estimate Causal Effects of SSDI Receipt." American Economic Review 103 (5): 1797-1829.

McCrary, Justin. 2008. "Manipulation of the running variable in the regression discontinuity design: A density test." Journal of Econometrics 142 (2): 698-714. 
Medicaid and CHIP Program Information by State: Wisconsin. 2016. Centers for Medicare and Medicaid Services. https://www.medicaid.gov/medicaid/by-state/stateprofile.html?state=wisconsin (accessed April 27, 2016).

Meyer, Bruce D. 2002. "Labor Supply at the Extensive and Intensive Margins: The EITC, Welfare, and Hours Worked." American Economic Review 92 (2): 373-79.

Moffitt, Robert A. 2002. "Welfare programs and labor supply." In Handbook of Public Economics, Vol. 4, edited by Alan J. Auerbach and Martin Feldstein, 2393-2430. Amsterdam: North-Holland.

-Moffitt, Robert, and Barbara Wolfe. 1992. "The Effect of the Medicaid Program on Welfare Participation and Labor Supply." Review of Economics and Statistics 74 (4): 615-26.

-Montgomery, E., and J. C. Navin. 2000. "Cross-state variation in Medicaid programs and female labor supply." Economic Inquiry 38 (3): 402-18.

Parsons, Donald O. 1991. "The Health and Earnings of Rejected Disability Insurance Applicants: Comment.” American Economic Review 81 (5): 1419-26.

-Propper, Carol. 1990. "Contingent Valuation of Time Spent on NHS Waiting Lists." Economic Journal 100 (400): 193-99.

-Propper, Carol. 1995. "The Disutility of Time Spent on the United Kingdom's National Health Service Waiting Lists." Journal of Human Resources 30 (4): 677-700.

Ruggles, Steven, J. Trent Alexander, Katie Genadek, Ronald Goeken, Matthew B. Schroeder, and Matthew Sobek. 2015. Integrated Public Use Microdata Series: Version 6.0 [Machine-readable database]. Minneapolis: University of Minnesota. http://doi.org/10.18128/D010.V6.0.

Smith, Jessica C., and Carla Medalia. 2015. Health Insurance Coverage in the United States: 2014. United States Census Bureau. Washington, DC, September.

-Smith, Jeffrey A., and Petra E. Todd. 2005. "Does matching overcome LaLonde's critique of nonexperimental estimators?" Journal of Econometrics 125 (1): 305-53.

-Stephens, Jessica, Samantha Artiga, Robin Rudowitz, Anne Jankiewicz, and David Rousseau. 2013. "Medicaid Expansion under the Affordable Care Act." Journal of American Medical Association 309 (12): 1219.

-Strumpf, Erin. 2011. "Medicaid's effect on single women's labor supply: Evidence from the introduction of Medicaid." Journal of Health Economics 30 (3): 531-48.

- Yelowitz, Aaron S. 1995. "The Medicaid Notch, Labor Supply, and Welfare Participation: Evidence from Eligibility Expansions." Quarterly Journal of Economics 110 (4): 909-39.

-Zissimopoulos, Julie M., and Lynn A. Karoly. 2007. "Transitions to self-employment at older ages: The role of wealth, health, health insurance and other factors." Labour Economics 14 (2): 269-95. 